\title{
Lignin fast pyrolysis: Results from an international collaboration
}

D.J. Nowakowski ${ }^{a}$, A.V. Bridgwater ${ }^{a}$, D.C. Elliott ${ }^{b_{*}}$, D. Meier ${ }^{c}$, P. de Wild $^{d}$

a Aston University, Birmingham, UK

b Pacific Northwest National Laboratory, Chemical and Biological Process Development,Richland, USA

c VTI - Institute of Wood Technology and Wood Biology, Hamburg, Germany

d ECN, The Netherlands

Presented in Journal of Analytical and Applied Pyrolysis 


\title{
Lignin fast pyrolysis: Results from an international collaboration
}

\author{
D.J. Nowakowski ${ }^{a}$, A.V. Bridgwater ${ }^{a}$, D.C. Elliott ${ }^{\mathrm{b}, *}$, D. Meier ${ }^{\mathrm{c}}$, P. de Wild ${ }^{\mathrm{d}}$ \\ a Aston University, Birmingham, UK \\ b Pacific Northwest National Laboratory, Chemical and Biological Process Development, P.0. Box 999, MSIN P8-60, Richland, WA 99352, USA \\ c $v$ TI - Institute of Wood Technology and Wood Biology, Hamburg, Germany \\ d ECN, The Netherlands
}

\section{A R T I C L E I N F O}

\section{Article history:}

Received 29 July 2009

Accepted 18 February 2010

Available online $\mathrm{xxx}$

\section{Keywords:}

Fast pyrolysis

Lignin

Bio-oil

Fluidized-bed

\begin{abstract}
A B S T R A C T
An international study of fast pyrolysis of lignin was undertaken. Fourteen laboratories in eight different countries contributed. Two lignin samples were distributed to the laboratories for analysis and bench-scale process testing in fast pyrolysis. Analyses included proximate and ultimate analysis, thermogravimetric analysis, and analytical pyrolysis. The bench-scale test included bubbling fluidized-bed reactors and entrained-flow systems. Based on the results of the various analyses and tests it was concluded that a concentrated lignin (estimated at about 50\% lignin and 50\% cellulose) behaved like a typical biomass, producing a slightly reduced amount of a fairly typical bio-oil, while a purified lignin material was difficult to process in the fast pyrolysis reactors and produced a much lower amount of a different kind of bio-oil. It was concluded that for highly concentrated lignin feedstocks new reactor designs will be required other than the typical fluidized-bed fast pyrolysis systems.
\end{abstract}

(c) 2010 Elsevier B.V. All rights reserved.

\section{Introduction}

Lignin is the second most abundant biomass component and the only renewable aromatic resource in nature. Lignin pyrolysis has been studied for almost 100 years with the focus on two different aspects: (1) unravelling the structure of the aromatic biopolymer, and (2) production of monomeric phenols. Good overviews on both pathways covering the years 1920-1980 are given by Goldstein [1] and Allan and Mattila [2]. In the past 25 years little attention has been paid to the use lignin as chemical resource. This time period has been recently reviewed by Amen-Chen et al. [3]. Lignin was rather used for studying degradation mechanisms by advanced pyrolysis methods combined with hyphenated separation and detection systems (GC/MS). The current understanding of the influence of pyrolysis conditions on the kinetics of lignin pyrolysis was recently investigated by Britt et al. [4]. Only recently, with the upcoming focus on biorefineries, lignin has gained new interest as chemical resource, as again the supply of fossil feedstocks is becoming more and more insecure and expensive.

On the other hand, in the past 20 years fast pyrolysis techniques have been developed for the conversion of whole plant biomass into a liquid (bio-oil) using mainly fluidized-bed reactors from laboratory to demonstration scale [5].
Therefore, the objectives of this international study were to attempt to carry out fast pyrolysis of several lignin samples and analyse the products in order to firstly establish the potential for this method of lignin processing and secondly to compare procedures and results. The research was carried out in the IEA Bioenergy Agreement Pyrolysis Task 34 - PyNe. This paper summarises results from the tests performed in the participating laboratories.

Fourteen laboratories agreed to participate in the project and each was supplied with samples of two lignins. The participants included:

- Aston University, UK

- Pacific Northwest National Laboratory, USA

- vTI-Institute of Wood Technology and Wood Biology, Germany

- Cirad- Forêt, France

- ECN, The Netherlands

- Forschungszentrum Karlsruhe GmbH, Germany

- IFP-Lyon, France

- National Renewable Energy Laboratory, USA

- STFI-Packforsk AB, Sweden

- University of Napoli, Italy

- University of Nottingham, UK

- University of Twente, The Netherlands

- USDA Eastern Regional Research Center, USA

- VTT Technical Research Centre of Finland, Finland

The analyses and tests performed can be categorized as shown in Table 1. The collaboration focused on bench-scale testing of the

\footnotetext{
* Corresponding author. Tel.: +1 509375 2248; fax: +1 5093724732

E-mail address: dougc.elliott@pnl.gov (D.C. Elliott).
} 
Table 1

Collaborative efforts in lignin pyrolysis.

\begin{tabular}{ll}
\hline & $\begin{array}{l}\text { Participating laboratory } \\
\text { number }\end{array}$ \\
\hline $\begin{array}{l}\text { Analysis } \\
\quad \text { Proximate and ultimate }\end{array}$ & $1,5,8,9,13$ \\
Thermogravimetric & $1,2,3,6$ \\
Analytical pyrolysis & $1,5,8,14$ \\
Process testing & \\
Continuous fluid bed, successful, ALM & $1,3,4$ \\
Continuous fluid bed, unsuccessful, ALM & $5,6,10,12$ \\
Entrained flow (high temp.), successful, ALM & 5 \\
Batch fluid bed, successful, ALM & 13 \\
Batch fluid bed, unsuccessful, ALM & 11,12 \\
Continuous fluid bed, successful, ETEK & $1,3,4,12$ \\
Continuous fluid bed, unsuccessful, ETEK & 5 \\
Entrained flow (high temp.), successful, ETEK & 5 \\
Batch fluid bed, successful, ETEK & 13 \\
\hline
\end{tabular}

lignin feedstocks, but supporting analyses also provided important information about the two lignins. Of the 9 laboratories with small fast pyrolysis reactor systems who attempted fast pyrolysis of the lignin feedstocks, seven laboratories provided fast pyrolysis processing results. The others reported failure to obtain any meaningful results arising from handling problems at high temperature.

Two lignin feedstocks were provided to the participating laboratories along with a specification of requested analyses as provided in Table 2 and a requested pyrolysis test data sheet, shown in Table 3. Two types and sources of lignin were evaluated:

1. A sulfur-free lignin obtained from annually harvested nonwoody plants (wheat straw and sarkanda grass Saccharum munja). The pulping method was the soda pulping process (aqueous $\mathrm{NaOH}$ ). It was a highly purified lignin recovered by precipitation, followed by washing and drying.

2. A concentrated lignin material which was a residue from ethanol production by weak acid hydrolysis of softwood. This lignin contained a significant fraction of cellulose and hemicellulose degradation products and was not purified.

\section{Lignin feedstock descriptions and characteristics}

Two types and sources of lignin were evaluated:

1. The ALM lignin, manufactured by Asian Lignin Manufacturing India Pvt. Ltd., SCO 26-27, 1st Floor, Sector 8-C, Chandigarh 160009 , India, was a sulfur-free lignin obtained from annually harvested non-woody plants (wheat straw and sarkanda grass S. munja). It was a co-product in the manufacture of pulp for printing and writing papers. The pulping method was the soda pulping process using aqueous $\mathrm{NaOH}$. The properties of the ALM lignin, provided by the manufacturer, are presented in Table 4 .

Table 2

Analytical specification for lignin pyrolysis tests.

\begin{tabular}{|c|c|c|}
\hline & Method & Reporting unit \\
\hline \multicolumn{3}{|l|}{ Feedstock } \\
\hline Moisture content of lignin & Dry at $60^{\circ} \mathrm{C}$ in vacuum oven & wt.\% moisture based on as-received lignin \\
\hline \multicolumn{3}{|l|}{ Product bio-oil } \\
\hline Water content & Karl Fischer Titration & wt.\% water based on wet bio-oil \\
\hline Viscosity & Capillary or rotary viscosimeter, 2 temp. @ 20 and $40^{\circ} \mathrm{C}$ & cSt @ 20 and $40^{\circ} \mathrm{C}$ \\
\hline Solids in bio-oil & Insolubles in ethanol, filter pore size $3 \mu \mathrm{m}$ or lower & wt.\% based on wet oil \\
\hline $\mathrm{pH}$ & Use pH-meter & $\mathrm{pH}$ unit \\
\hline Elemental analysis & Elemental analyser (complete oxidation) & wt.\% C, wt.\% H, wt.\% N, wt.\% O, based on wet bio-oil \\
\hline Pyrolytic lignin & $\begin{array}{l}\text { Add } 60 \mathrm{ml} \text { oil to } 1 \mathrm{~L} \text { of ice-cooled water under stirring, filter and dry } \\
\text { precipitate below } 60^{\circ} \mathrm{C}\end{array}$ & wt.\% based on wet bio-oil \\
\hline Gas chromatography & $\begin{array}{l}\text { Column type DB } 1701 \text {, dimensions: } 60 \mathrm{~m} \times 0.25 \mathrm{~mm} \text {, film thickness: } \\
0.25 \mu \mathrm{m} \text {, injector: } 250^{\circ} \mathrm{C} \text {, split } 1: 30 \mathrm{FID} \text { detector: } 280^{\circ} \mathrm{C} \text {, oven } \\
\text { programme: } 45^{\circ} \mathrm{C}, 4 \mathrm{~min} \text { const., } 3^{\circ} \mathrm{C} / \mathrm{min} \text { to } 280^{\circ} \mathrm{C} \text {, hold } 20 \mathrm{~min} \\
\text { sample conc.: } 6 \text { wt. } \% \text {, solvent acetone }\end{array}$ & \\
\hline
\end{tabular}

Table 3

Requested data from fast pyrolysis tests.

\begin{tabular}{|c|c|c|c|}
\hline & Results & Method used & Difficulties and suggestions \\
\hline \multicolumn{4}{|l|}{ Sample name: } \\
\hline \multicolumn{4}{|l|}{ Date of arrival: } \\
\hline Moisture content of lignin & wt.\% & & \\
\hline \multicolumn{4}{|l|}{ Pyrolysis reactor description } \\
\hline \multicolumn{4}{|l|}{ Feeder description } \\
\hline \multicolumn{4}{|l|}{ Bed type } \\
\hline \multicolumn{4}{|l|}{ Carrier gas } \\
\hline \multicolumn{4}{|l|}{ Bio-oil collection system } \\
\hline Temperature & ${ }^{\circ} \mathrm{C}$ & & \\
\hline Residence time at temperature & $\mathrm{s}$ & & \\
\hline Bio-oil yield & wt.\% & & \\
\hline Char yield & wt.\% & & \\
\hline Gas yield & wt.\% & & \\
\hline Water content & wt.\% (based on bio-oil as produced) & & \\
\hline \multirow[t]{2}{*}{ Viscosity of bio-oil } & cSt @ $20^{\circ} \mathrm{C}$ & & \\
\hline & cST@ $900^{\circ} \mathrm{C}$ & & \\
\hline $\begin{array}{l}\text { Solids based on wet bio-oil } \\
\mathrm{pH}\end{array}$ & wt.\% & & \\
\hline Elemental analysis & wt.\% C & & \\
\hline \multirow[t]{2}{*}{ (based on bio-oil as produced) } & wt.\% H & & \\
\hline & wt.\% O & & \\
\hline Pyrolytic lignin & wt.\% (based on bio-oil as produced) & & \\
\hline
\end{tabular}


Table 4

ALM lignin properties ${ }^{\mathrm{a}}$.

\begin{tabular}{ll}
\hline Solids content & $95+\%$ \\
Composition (dry basis) & $>94 \%$ lignin, $4 \%$ protein, $<2 \%$ hemicelluloses sugar, \\
& $<0.2 \%$ cellulose, $<4 \%$ ash \\
pH (10\% slurry) & $2.5-4$ \\
Functional groups & $8-10 \%$ carboxyl, $2-3 \%$ aromatic $\mathrm{OH}, 3-4 \%$ aliphatic \\
& $\mathrm{OH}$ \\
Particle size & Approximately $100-110 \mu \mathrm{m}$ \\
Molecular weight & $M_{\mathrm{N}} 1000 \mathrm{Da}, \mathrm{M}_{\mathrm{W}} 2500-3400 \mathrm{Da}$ \\
Appearance & Low odour, brown powder \\
Thermal behavior & Softening temperature $\sim 120-180{ }^{\circ} \mathrm{C}$ \\
Bulk density & $450 \mathrm{~kg} / \mathrm{m}^{3}$ \\
Solubility & Very low solubility in water, high solubility in \\
& aqueous alkali, CMF, $2-\mathrm{methoxyethanol,} \mathrm{furfuryl}$ \\
& alcohol, $90 \%$ acetone $/ 10 \% \mathrm{H}_{2} \mathrm{O}$ \\
\hline
\end{tabular}

a http://www.asianlignin.com/pages/products1.html [6].

The ALM lignin was supplied via Granit SA, Lausanne, Switzerland.

2. The ETEK lignin from Sweden was a residue from ethanol production by a 2-stage weak acid hydrolysis of softwood. This lignin was not a high-purity product but contained carbohydrate polymer degradation products (up to $50 \%$ cellulosic) as well as lignin.

The lignins are shown in Fig. 1.

\section{Ultimate and proximate analysis of lignin feedstocks}

The elemental and ash content analytical results from the manufacturers and five of the participating laboratories are presented for both types of lignin in Table 5 . The Asian lignin had higher carbon and lower oxygen content than the ETEK lignin, which correlates with a higher lignin content. The ALM lignin also had significantly
Table 6

Inorganic components determined in ETEK and ALM lignins.

\begin{tabular}{lcl}
\hline Inorganic component $(\mathrm{ppm})$ & ETEK lignin & ALM lignin \\
\hline $\mathrm{Na}$ & 25 & 745 \\
$\mathrm{~K}$ & 220 & 439 \\
$\mathrm{Mg}$ & $<20$ & 192 \\
$\mathrm{Ca}$ & 221 & 243 \\
$\mathrm{Si}$ & $<20$ & 165 \\
\hline
\end{tabular}

higher ash content than the ETEK lignin as expected due to its origin from straw and grass.

Some inorganic components including sodium, calcium, magnesium, potassium and silica were determined in ETEK and ALM lignins. Concentrations of these components as provided by Laboratory 9 are given in Table 6 .

\section{Thermogravimetric analysis of lignin feedstocks}

Thermogravimetric analysis (TGA) is a pyrolytic method which has often been applied to biomass and biomass components. However, TGA is performed in a heating environment very different from fast pyrolysis. The slow heating rate used is an attempt to allow the chemistry in the sample to equilibrate as it moves through the temperature range of interest. Fast pyrolysis is inherently a non-equilibrium process.

\subsection{Laboratory 1}

A Perkin Elmer Pyris 1 thermobalance was used to carry out pyrolysis under dynamic heating for both lignin samples (2-3 mg) at a heating rate of $25^{\circ} \mathrm{C} / \mathrm{min}$ heating from ambient temperatures to $900^{\circ} \mathrm{C}$ in nitrogen flow. Graphs of (TGA) and its derivative, Dif-
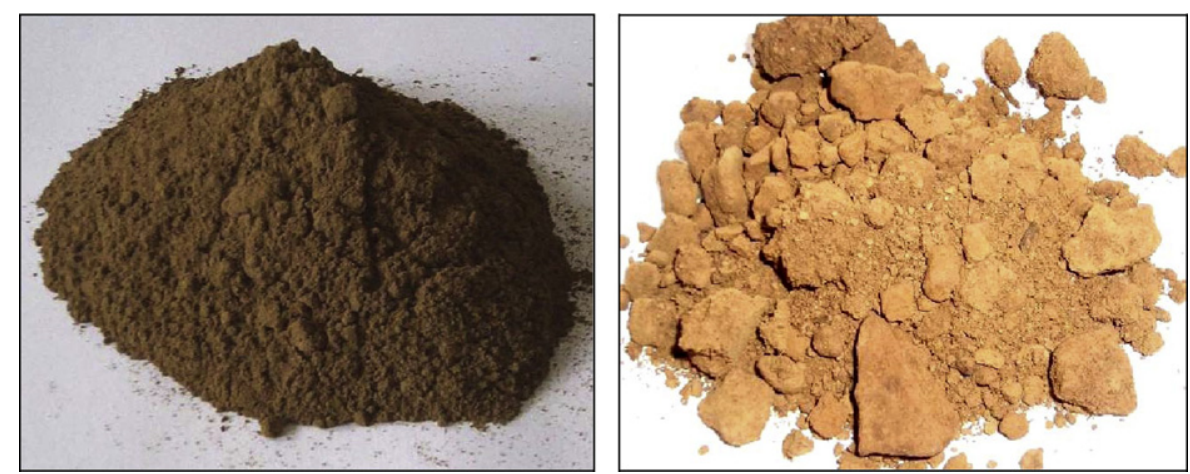

Fig. 1. ALM lignin (left) and ETEK lignin (right).

Table 5

Elemental and ash content analysis.

\begin{tabular}{|c|c|c|c|c|c|c|c|c|}
\hline wt.\% & Lab & C & $\mathrm{H}$ & $\mathrm{N}$ & $S$ & 0 & Total & Ash \\
\hline ALM & ALM & 61 & 7 & 0.9 & $<0.03$ & 31 & 99.9 & $<4 \%$ \\
\hline ALM & 1 & 62.32 & 5.91 & 0.66 & $<0.10$ & $31.01^{\mathrm{a}}$ & 100.00 & 1.31 \\
\hline ALM & 8 & 63.7 & 6.3 & 1.3 & ND & $28.7^{\mathrm{a}}$ & 100.0 & 1.2 \\
\hline ALM & 9 & 63.81 & 5.82 & 1.21 & 0.31 & 26.81 & 97.96 & 1.15 \\
\hline ALM & 13 & 62.35 & 6.12 & 2.63 & ND & $22.90^{\mathrm{a}}$ & 94.0 & 6 \\
\hline ALM & 5 & 62.05 & 5.95 & ND & ND & $32.00^{\mathrm{a}}$ & 100.00 & ND \\
\hline ETEK & ETEK & 54.28 & 6.11 & ND & 0.17 & $39.44^{\mathrm{a}}$ & 100.00 & 0.2 \\
\hline ETEK & 1 & 53.62 & 5.82 & $<0.10$ & $<0.10$ & $40.37^{a}$ & 100.00 & 0.5 \\
\hline ETEK & 8 & 58.0 & 5.9 & 0.2 & ND & $35.9^{a}$ & 100.0 & 0.2 \\
\hline ETEK & 9 & 57.18 & ND & 0.12 & 0.19 & ND & ND & 0.62 \\
\hline ETEK & 13 & 51.33 & 5.7 & 1.55 & ND & $37.42^{\mathrm{a}}$ & 96.0 & 4 \\
\hline ETEK & 5 & 53.71 & 6.03 & ND & ND & $40.26^{a}$ & 100.00 & ND \\
\hline
\end{tabular}

a By difference. 


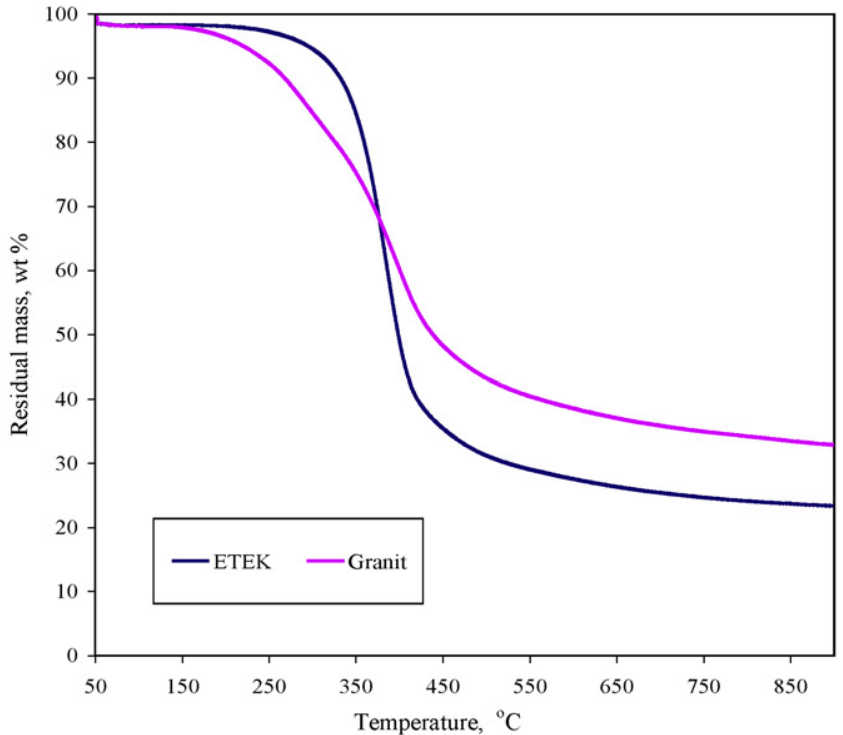

Fig. 2. TGA mass loss profiles of ETEK and ALM (Granit) lignins.

ferential Thermal Analysis (DTA) were produced for each sample and are presented in Figs. 2 and 3, respectively. The TGA and DTA graphs illustrate a much wider range of decomposition for the ALM lignin compared to the ETEK lignin.

\subsection{Laboratory 3}

The thermal behaviors of lignins were also investigated by TGA and DTA with a Mettler Toledo TGA 850, featuring automated temperature and weight control and data acquisition. Prior to the analysis, samples were dried overnight in a stove at $105^{\circ} \mathrm{C}$ under air. The sample weight amounted to approximately $15 \mathrm{mg}$. In this case the samples were heated at a slower rate of $5^{\circ} \mathrm{C} / \mathrm{min}$ from ambient temperatures to $500^{\circ} \mathrm{C}$ in nitrogen flow. Higher temperatures were not scanned. TGA and DTA profiles for ALM and ETEK lignins are given in Figs. 4 through 7.

\subsection{Other laboratories}

Two other laboratories also performed TGA analyses. Laboratory 2 did TGA in conjunction with Differential Scanning Calorimetry

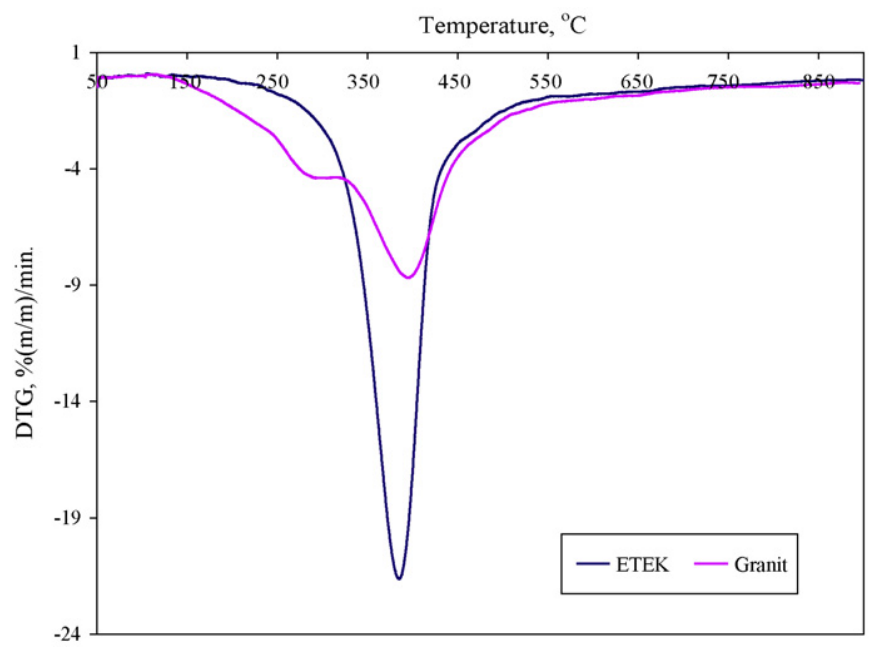

Fig. 3. DTA profiles of ETEK and ALM (Granit) lignins.

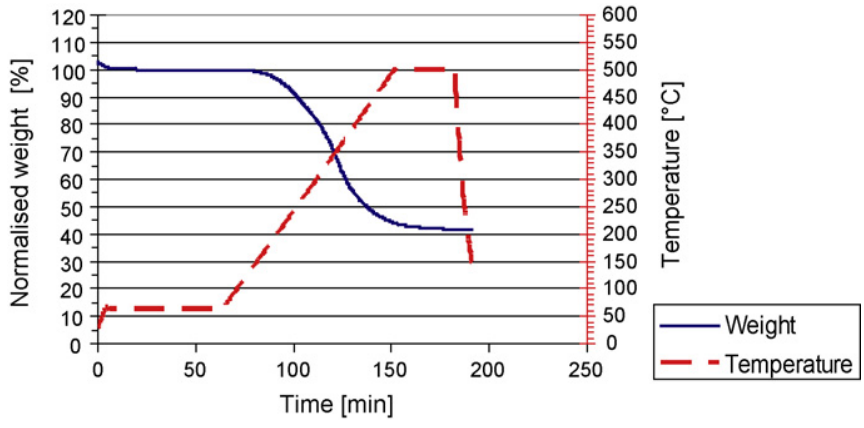

Fig. 4. TGA profile for ALM lignin.

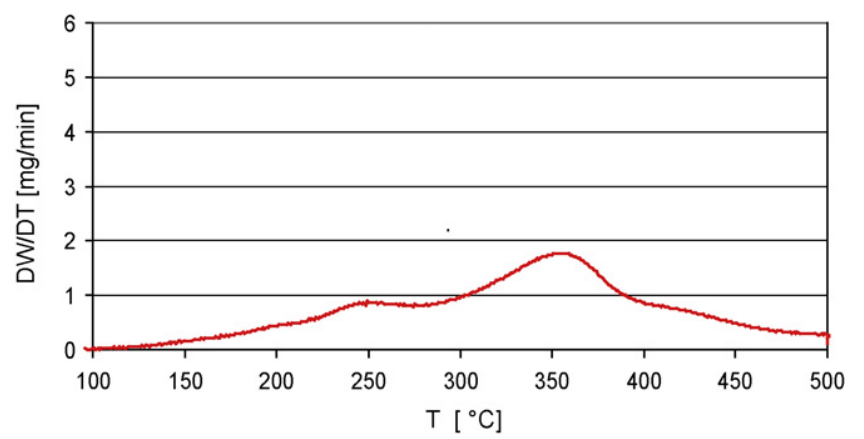

Fig. 5. DTA profile for ALM lignin.

(DSC). The two samples were tested as-received without drying. The data curves look much the same as shown above with the more gradual decomposition of the ALM beginning at a lower temperature. Laboratory 6 performed a TGA on the ALM lignin only. The heating profile included a $1 \mathrm{~h}$ time at $20^{\circ} \mathrm{C}$ followed by heating at $10^{\circ} \mathrm{C} / \mathrm{min}$ to $700^{\circ} \mathrm{C}$ and followed by holding for $1 \mathrm{~h}$.

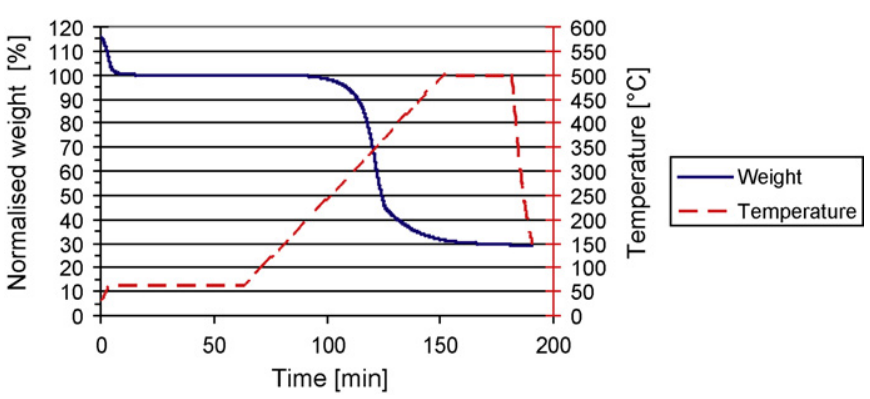

Fig. 6. TGA profile for ETEK lignin.

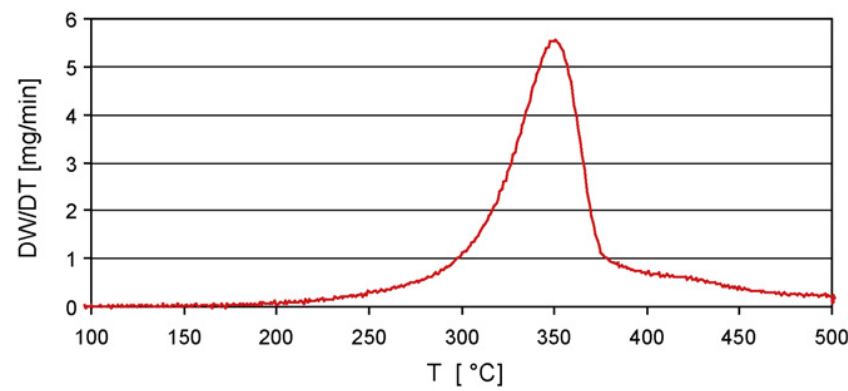

Fig. 7. DTA profile for ETEK lignin. 
Table 7

Comparison of TGA data.

\begin{tabular}{|c|c|c|c|c|}
\hline & $1\left(25^{\circ} \mathrm{C} / \mathrm{min}\right)$ & $2\left(100^{\circ} \mathrm{C} / \mathrm{min}\right)$ & $3\left(5^{\circ} \mathrm{C} / \mathrm{min}\right)$ & $6\left(10^{\circ} \mathrm{C} / \mathrm{min}\right)$ \\
\hline \multicolumn{5}{|l|}{ ALM (dry basis) } \\
\hline Volatiles to $500^{\circ} \mathrm{C}$ & 56.9 & 54.8 & 59.5 & 48.6 \\
\hline Total volatiles (temp.) & $66.9 @ 900 \circ \mathrm{C}$ & 66.5@1384 C & $59.5 @ 500$ C & $59.6 @ 700 \circ \mathrm{C}$ \\
\hline ETEK (dry basis) & & & & Not analysed \\
\hline Volatiles to $500^{\circ} \mathrm{C}$ & 68.8 & 52.1 & 70.5 & \\
\hline Total volatiles (temp.) & 76.6@900॰C & $57.0 @ 1384^{\circ} \mathrm{C}$ & $70.5 @ 500$ ○C & \\
\hline
\end{tabular}

\subsection{Summary of TGA results for lignin feedstocks}

All the data sets can be compared in tabular form as shown in Table 7. The heating rate affects the outcome with the slowest heating rate (longest residence time) achieving the highest volatility. None of these heating rates even approaches that seen typically in fast pyrolysis $\left(300-1000^{\circ} \mathrm{C} / \mathrm{s}\right.$ ) and should not be considered as a reasonable representation of that chemistry. It is also interesting to compare these TGA curves with those in the literature [7] for other biomass and biomass components. The ALM curve appears very similar to a lignin curve, while the ETEK shows a stronger correlation to a cellulose or a biomass with a large cellulose component.
Table 8

Analytical pyrolysis results.

\begin{tabular}{lrr}
\hline Results on a carbon feed basis & ETEK & GRANIT \\
\hline Carbon in the residue (mass of the residue - mass & $58.7 \%$ & $65.0 \%$ \\
$\quad$ of the ash) & & \\
Carbon in GC-eluted pyrolysis gases & $0.8 \%$ & $0.4 \%$ \\
Carbon in GC-eluted liquids & $3.9 \%$ & $1.8 \%$ \\
Loss of carbon in the system & $36.7 \%$ & $32.9 \%$ \\
\hline
\end{tabular}

Table 9

Yields of Py-GC-MS decomposition products.

\begin{tabular}{|c|c|c|c|c|c|c|}
\hline ID & Name & Origin & Group & RT & ALM (avg \%) & ETEK (avg \%) \\
\hline 1 & 2,3-Butanedione & $\mathrm{C}$ & & 6.13 & $0.48 \%$ & $2.04 \%$ \\
\hline 2 & 2-Butanone & $\mathrm{C}$ & & 6.21 & $0.48 \%$ & $0.00 \%$ \\
\hline 3 & Benzene & $\mathrm{L}$ & $\mathrm{HC}$ & 6.84 & $0.15 \%$ & $0.10 \%$ \\
\hline 4 & Hydroxyacetaldehyde & $\mathrm{C}$ & & 7.20 & $0.00 \%$ & $2.92 \%$ \\
\hline 5 & Acetic acid & $\mathrm{C}$ & & 8.52 & $1.46 \%$ & $3.00 \%$ \\
\hline 6 & 1-Hydroxy-2-propanone & $\mathrm{C}$ & & 9.78 & $0.16 \%$ & $3.80 \%$ \\
\hline 7 & Toluene & $\mathrm{L}$ & $\mathrm{HC}$ & 10.20 & $0.63 \%$ & $0.13 \%$ \\
\hline 8 & Ethylbenzene & $\mathrm{L}$ & $\mathrm{HC}$ & 14.41 & $0.10 \%$ & $0.00 \%$ \\
\hline 9 & p-Xylene & $\mathrm{L}$ & $\mathrm{HC}$ & 14.79 & $0.00 \%$ & $0.07 \%$ \\
\hline 10 & Butanedial & $\mathrm{C}$ & & 16.33 & $0.00 \%$ & $1.78 \%$ \\
\hline 11 & Styrene & $\mathrm{L}$ & $\mathrm{HC}$ & 16.62 & $0.39 \%$ & $3.22 \%$ \\
\hline 12 & Furfural & $\mathrm{C}$ & & 17.24 & $1.05 \%$ & $3.92 \%$ \\
\hline 13 & 2-Furanmethanol & $\mathrm{C}$ & & 19.53 & $0.28 \%$ & $1.30 \%$ \\
\hline 14 & Cyclohexanone & $\mathrm{C}$ & & 22.84 & $0.00 \%$ & $3.27 \%$ \\
\hline 15 & 5-Methyl-2-furancarboxaldehyde & $\mathrm{C}$ & & 24.20 & $0.00 \%$ & $0.77 \%$ \\
\hline 16 & $2(5 \mathrm{H})$-Furanone & $\mathrm{C}$ & & 25.56 & $0.07 \%$ & $1.71 \%$ \\
\hline 17 & Phenol & $\mathrm{L}$ & Phenol & 29.45 & $3.57 \%$ & $0.51 \%$ \\
\hline 18 & Guaiacol & L-G & & 30.17 & $9.21 \%$ & $11.55 \%$ \\
\hline 19 & 2-Methyl phenol & $\mathrm{L}$ & Phenol & 31.72 & $0.69 \%$ & $0.61 \%$ \\
\hline 20 & 2,6-Dimethyl phenol & $\mathrm{L}$ & Phenol & 32.37 & $0.05 \%$ & $0.12 \%$ \\
\hline 21 & 4-Methyl phenol & $\mathrm{L}$ & Phenol & 33.37 & $1.97 \%$ & $0.34 \%$ \\
\hline 22 & 4-Methylguaiacol & L-G & & 34.97 & $8.87 \%$ & $15.07 \%$ \\
\hline 23 & Dimethyl phenols & $\mathrm{L}$ & Phenol & 35.50 & $0.18 \%$ & $2.01 \%$ \\
\hline 24 & 2,3,5-Trimethyl phenol & $\mathrm{L}$ & Phenol & 36.35 & $0.05 \%$ & $0.06 \%$ \\
\hline 25 & 3-Ethyl- or 4-Ethyl phenol & $\mathrm{L}$ & Phenol & 37.32 & $3.50 \%$ & $0.05 \%$ \\
\hline 26 & 2-Ethyl phenol & $\mathrm{L}$ & Phenol & 38.43 & $0.15 \%$ & $0.10 \%$ \\
\hline 27 & 4-Ethyl guaiacol & L-G & & 38.70 & $6.49 \%$ & $5.07 \%$ \\
\hline 28 & 1,4:3,6-Dianhydro- $\alpha$-D-glucopyranose & $\mathrm{C}$ & & 40.17 & $0.00 \%$ & $1.56 \%$ \\
\hline 29 & 3-Methoxy-1,2-benzenediol & $\mathrm{L}$ & & 41.03 & $0.21 \%$ & $0.00 \%$ \\
\hline 30 & 4-Vinylguaiacol & L-G & & 41.14 & $22.87 \%$ & $4.95 \%$ \\
\hline 31 & Eugenol & L-G & & 42.18 & $0.60 \%$ & $1.22 \%$ \\
\hline 32 & 1,2-Benzenediol & $\mathrm{L}$ & & 43.16 & $0.81 \%$ & $1.29 \%$ \\
\hline 33 & Syringol & L-S & & 43.46 & $10.74 \%$ & $0.00 \%$ \\
\hline 34 & 3-Methyl-1,2-Benzenediol & $\mathrm{L}$ & & 44.70 & $0.52 \%$ & $0.32 \%$ \\
\hline 35 & trans-Isoeugenol & L-G & & 46.55 & $3.31 \%$ & $5.01 \%$ \\
\hline 36 & 1,2,3-Trimethoxybenzene & $\mathrm{L}$ & & 47.16 & $7.13 \%$ & $0.00 \%$ \\
\hline 37 & Vanillin & L-G & & 47.44 & $1.42 \%$ & $4.92 \%$ \\
\hline 38 & Acetoguaiacone & $L-G$ & & 50.59 & $1.41 \%$ & $1.90 \%$ \\
\hline 39 & Guaiacylacetone & L-G & & 52.53 & $1.13 \%$ & $1.29 \%$ \\
\hline 40 & Coniferyl alcohol & $\mathrm{L}-\mathrm{G}$ & & 54.18 & $0.00 \%$ & $0.65 \%$ \\
\hline 41 & 1,6-Anhydro-beta-D-glucopyranose & $\mathrm{C}$ & & 55.99 & $0.60 \%$ & $13.40 \%$ \\
\hline 42 & Methoxyeugenol & L-S & & 56.88 & $2.51 \%$ & $0.00 \%$ \\
\hline 43 & Syringaldehyde & L-S & & 57.94 & $1.13 \%$ & $0.00 \%$ \\
\hline \multirow[t]{2}{*}{44} & Acetosyringone & L-S & & 60.27 & $5.68 \%$ & $0.00 \%$ \\
\hline & Total & & & & $100.00 \%$ & $100.00 \%$ \\
\hline
\end{tabular}

$\mathrm{C}=$ carbohydrates, $\mathrm{L}=$ lignin, $\mathrm{L}-\mathrm{G}=$ guaiacyl lignin, $\mathrm{L}-\mathrm{S}=$ syringyl lignin, $\mathrm{HC}=$ hydrocarbons . 


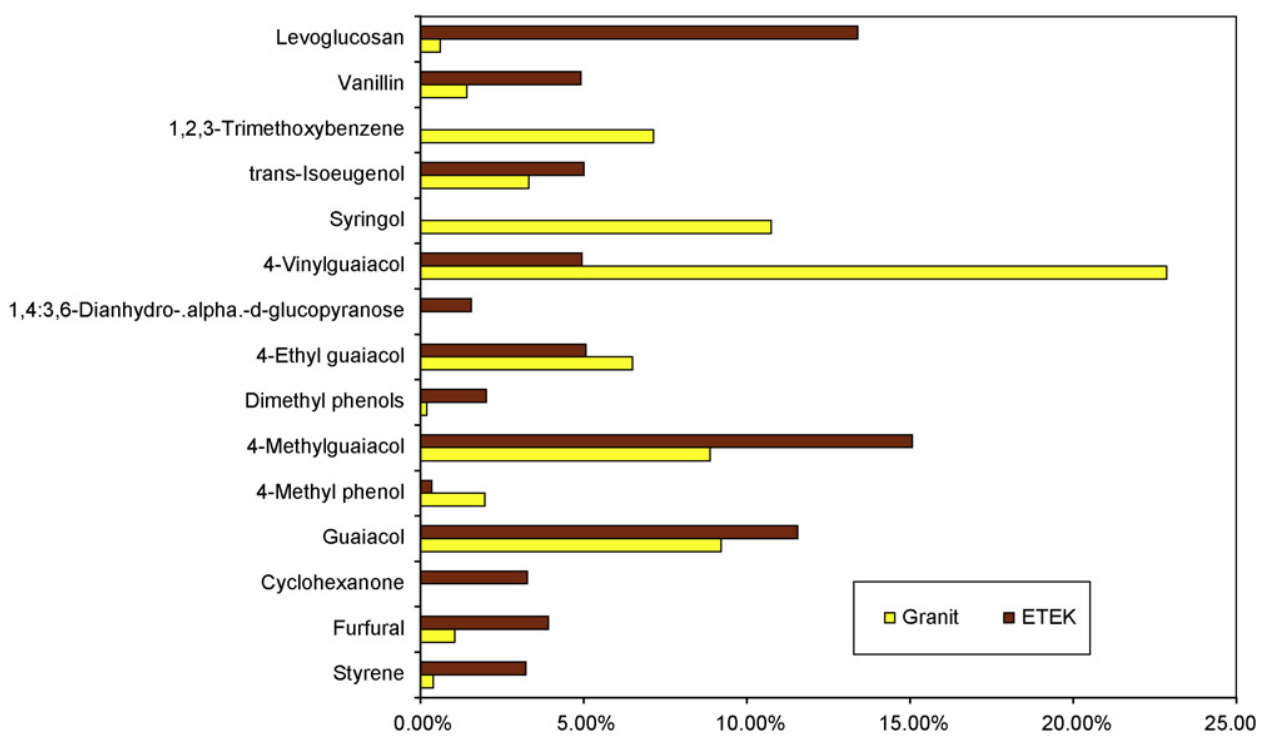

Fig. 8. Comparison of key pyrolytic decomposition markers from pyroprobe-GC/MS.

However, cellulose would be expected to leave a $10 \%$ residue or less at $500^{\circ} \mathrm{C}$, and the higher residue amount from these samples supports the lignin analysis.

\section{Analytical pyrolysis of lignin feedstocks}

The methods of analytical pyrolysis have also been applied to biomass materials. The resulting product can approach that of a fast pyrolysis reactor with careful attention to the instrumental operating conditions. An understanding the product components can be used to evaluate the structure of the biomass feedstock.

\subsection{Laboratory 8}

Lignin samples were pyrolyzed using CDS Instruments Pyroprobe 1000 pyrolyzer connected to an HP 5890 Series II gas chromatograph. The detector was an HP 9521A atomic emission detector (AED).

Samples were pyrolyzed in a quartz tube $(1.2 \mathrm{~cm} \times 1.0 \mathrm{~mm}$ i.d. $)$ at $500^{\circ} \mathrm{C}$ the heating rate was $1000^{\circ} \mathrm{C} / \mathrm{s}$ and the heating time was $20 \mathrm{~s}$. The interface temperature of the pyrolyzer was $300^{\circ} \mathrm{C}$. Pyrolysis products were swept to the injection port of the GC with helium carrier gas.

The chromatographic separation was carried out using an HP Ultra 1 fused silica capillary column $(50 \mathrm{~m} \times 0.32 \mathrm{~mm}$ i.d., film thick-

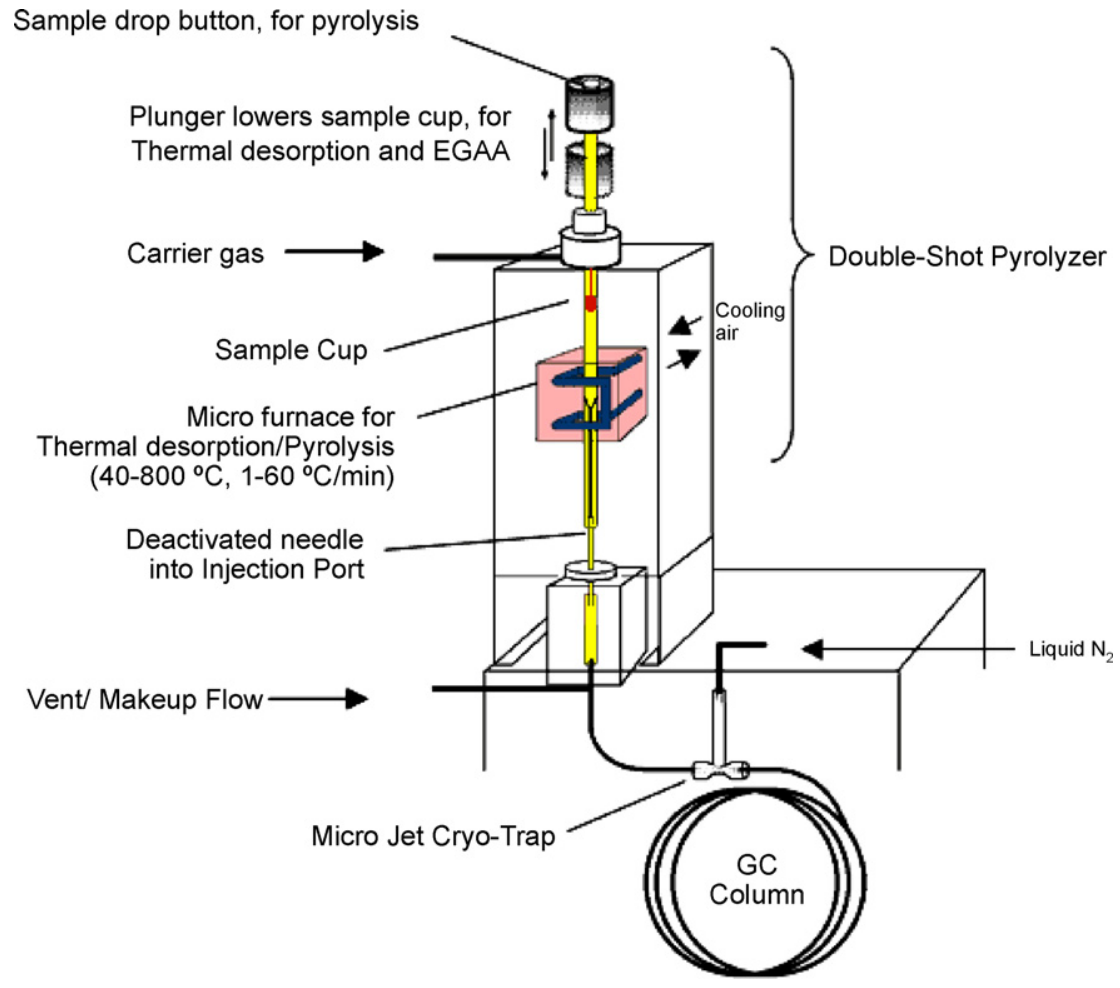

Fig. 9. Micro-oven pyrolyzer Py-GC device for lignin pyrolysis. 


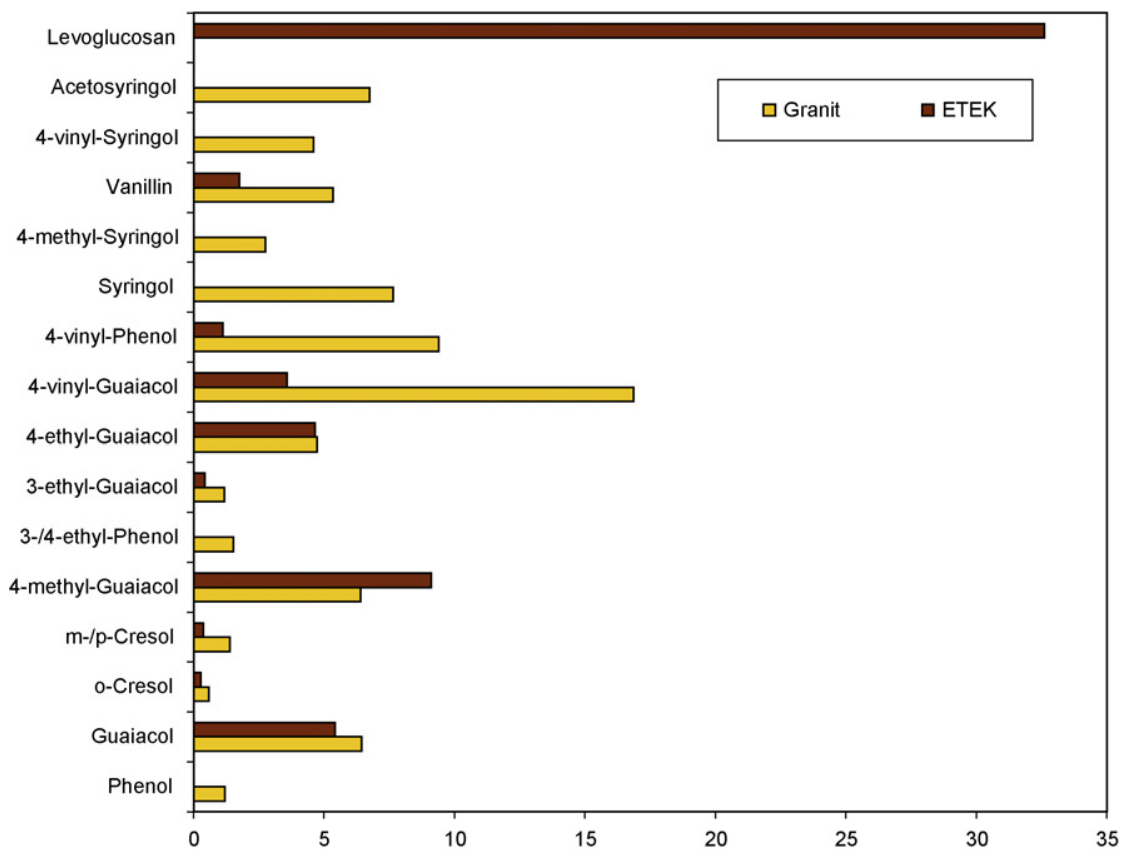

Fig. 10. Comparison of key pyrolytic decomposition markers from micro-oven pyrolyzer-GC/MS.

ness $0.52 \mu \mathrm{m}$ ). The oven temperature program was $3 \mathrm{~min}$ at $30^{\circ} \mathrm{C}$, $10^{\circ} \mathrm{C} / \mathrm{min}$ to $310^{\circ} \mathrm{C}$, and $25 \mathrm{~min}$ at $310^{\circ} \mathrm{C}$. The carrier gas was helium and the injector pressure was $125 \mathrm{kPa}$. Injector temperature was $300^{\circ} \mathrm{C}$.

For quantitative carbon and hydrogen determinations the AED's mass responses were calibrated by injecting benzene solution. The wavelengths used for hydrogen and carbon were 486.1 and $495.7 \mathrm{~nm}$, respectively. In pyrolysis the lignin was converted into GC-eluted compounds, pyrolysis residue and loss. The term 'loss' was used for high molecular mass compounds not eluted through the GC column but released from the lignin. In this study the GC-eluted compounds were classified into gases (light fraction) and liquids (heavy fraction). The retention time of $3.2 \mathrm{~min}$ was the upper limit of the gaseous fraction (just before the elution of n-pentane; b.p. $36^{\circ} \mathrm{C}$ ). The samples were weighed with a microbalance Sartorius SE 2F before the pyrolysis and the pyrolysis residue was weighed afterwards. The pyrolysis residue was assumed to be carbon. Total mass balances for carbon were calculated from the calibration results and the weighed masses. Pyrolysis results (yields) are given in Table 8.

The selected pyrolysis temperature $\left(500^{\circ} \mathrm{C}\right)$ gave very low GCeluted carbon mass. These lignin results differ very much from results with studies involving pine wood sawdust.

\subsection{Laboratory 1}

A CDS-2000 pyroprobe (Chemical Data Systems, USA) and CDS AS-2500 auto-sampler coupled to a gas chromatographer-mass spectrometer was used to characterize the lignin samples. The pyroprobe is an analytical scale pyrolysis unit which consists of an inductive heated coil to heat samples.

The sample (ca. $0.5 \mathrm{mg}$ ) was loaded in a fire polished quartz tube and placed in the centre of the inductive coil with an isothermal setting of $600{ }^{\circ} \mathrm{C}$ (due to a temperature difference of $100^{\circ} \mathrm{C}$ between the coil and the sample temperature) at a heating rate of $3000^{\circ} \mathrm{C} / \mathrm{s}$ with a pyrolysis time of $10 \mathrm{~s}$. The analysis was conducted in triplicates.

A gas chromatograph with a split ratio of $(1: 125)$ was used for compound separation. Both the injector and detector temperatures were at $280^{\circ} \mathrm{C}$ and the carrier velocity was at $38 \mathrm{~cm} / \mathrm{s}$. Separation was achieved using a semi polar column PP1701 or DB 1701 (60 m by $0.25 \mathrm{~mm}$ i.d. with a $0.25 \mu \mathrm{m}$ film thickness) with a chemical composition of $14 \%$ cyanopropyl-phenyl $86 \%$ dimethylpolysiloxane which shows a different selectivity to (phenyl) dimethylsiloxane phases because of the functional cyano groups. In order to give good product separation, the temperature program began at $45^{\circ} \mathrm{C}$ for $4 \mathrm{~min}$, followed by a heating rate of $4{ }^{\circ} \mathrm{C} / \mathrm{min}$ to $240^{\circ} \mathrm{C}$ and $39^{\circ} \mathrm{C} / \mathrm{min}$ to $280^{\circ} \mathrm{C}$.

Electron impact mass spectra were obtained by Perkin Elmer MS GOLD (UK) at $70 \mathrm{eV}$. The mass range from $\mathrm{m} / \mathrm{z} 28$ to 600 was scanned with a speed of $1.0 \mathrm{~s} /$ decade. Data processing was done by Perkin Elmer Turbo mass spectrometer version 6.0. The compounds from the chromatograms were identified by comparison of the mass spectra with the Perkin Elmer NIST computer library, together with literature data to obtain the highest likelihood of compound identification. The quoted percentages, presented in Table 9, are the average of the triplicate analyses based on the peak area of each identified compound divided by the total peak area of all identified compounds. Comparison of key pyrolytic decomposition markers for ETEK and ALM lignins is given in Fig. 8.

The percentages of the identified compounds derived from carbohydrates, lignin, etc. are presented in Table 10 . In addition the total percentages of identified compounds classed as hydrocarbons and phenols are also included in Table 10. It should be noted that only alkyl-phenols and not oxygenated phenols like guaiacol have been classed as phenols for this estimation.

Table 10

Origin of the compounds identified by Pyroprobe-GC/MS based on peak area.

\begin{tabular}{lrr}
\hline & \multicolumn{1}{c}{ ALM } & \multicolumn{1}{c}{ ETEK } \\
\hline Carbohydrates & $4.56 \%$ & $39.46 \%$ \\
Guaiacols & $57.81 \%$ & $51.62 \%$ \\
Syringols & $17.54 \%$ & $0.00 \%$ \\
Lignin & $20.09 \%$ & $8.92 \%$ \\
& $100.00 \%$ & $100.00 \%$ \\
Phenols & $10.15 \%$ & $3.79 \%$ \\
HC & $1.27 \%$ & $3.51 \%$ \\
\hline
\end{tabular}




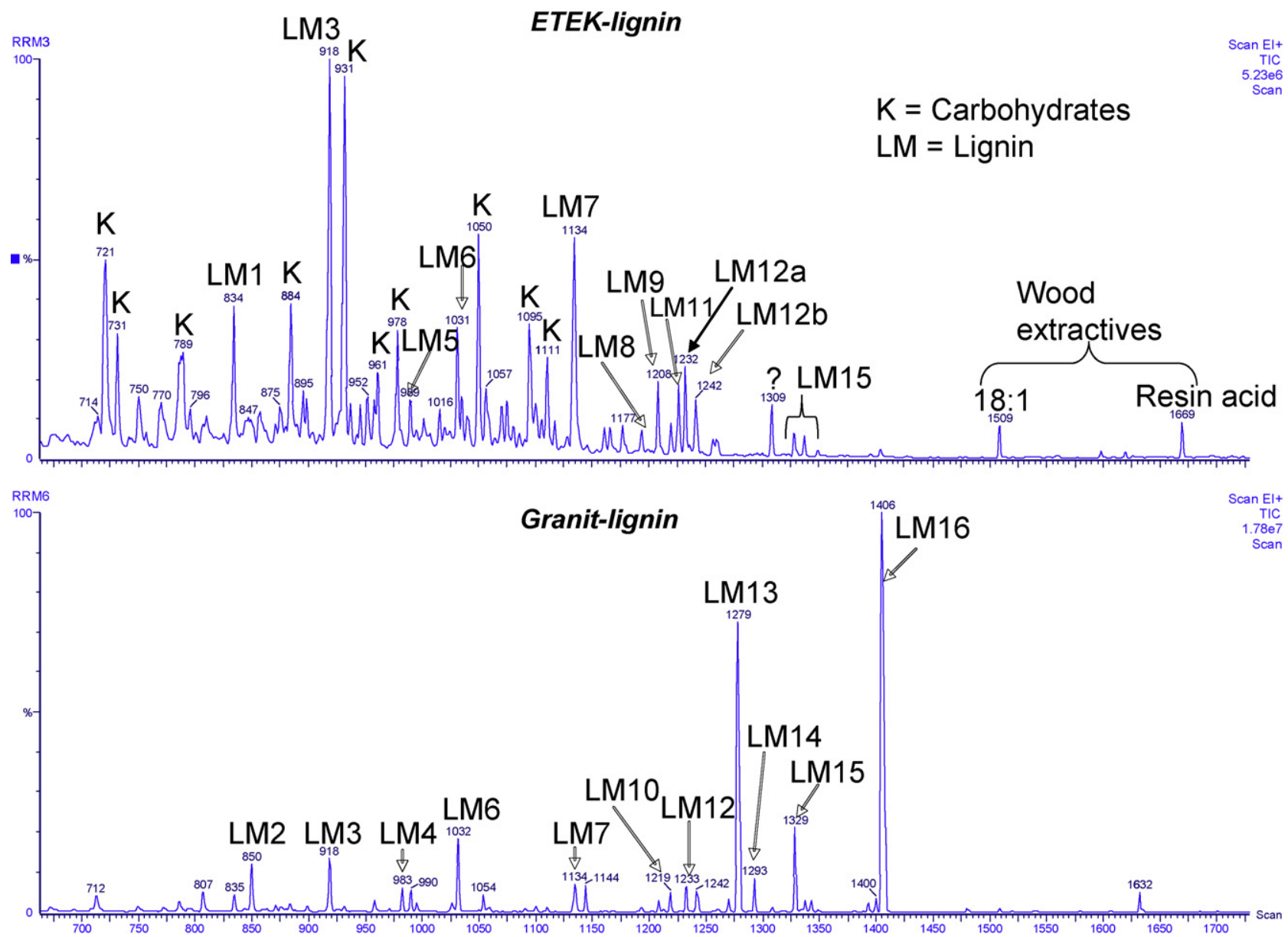

Fig. 11. Representative pyrograms of the lignin samples ETEK and ALM (Granit) performed with methylation (TMAH).

The significant amount of carbohydrate (cellulose and hemicellulose) degradation products (39.46\%), such as levoglucosan, identified in the ETEK's chromatograms, support the assumption that the ETEK lignin is not a pure lignin, in contrast to the ALM lignin that contains very small amounts. The highest amount of phenols was identified in the ALM lignin's chromatogram.

\subsection{Laboratory 5}

Analytical pyrolysis was performed in the Py-GC/MS system, which consisted of a micro-oven pyrolyzer (Double shot from Frontier Lab, Japan) equipped with an auto-sampler attached on an Agilent GC/MS device.

The following conditions were used:

\begin{tabular}{ll} 
Py. temp. & $450{ }^{\circ} \mathrm{C}$ \\
GC/MS & Agilent HP 6890/5972 \\
Carrier gas & Helium const. $2 \mathrm{ml} / \mathrm{min}$ \\
Column & Varian VF $1701 \mathrm{MS}, 60 \mathrm{~m} \times 0.25 \mathrm{~mm}$, film \\
& thickness $0.25 \mu \mathrm{m}$ \\
Column phase & $14 \%$ cyanopropyl-phenyl $86 \%$ \\
& dimethylpolysiloxan \\
Injector split ratio & $1: 30$ \\
Oven temperature program & Isothermal $45^{\circ} \mathrm{C}, 4$ min heat $3{ }^{\circ} \mathrm{C} / \mathrm{min}$ to $280^{\circ} \mathrm{C}$, \\
& hold $280^{\circ} \mathrm{C}$ for 15 min \\
Injector temp. & $250^{\circ} \mathrm{C}$ \\
Detector (FID) temp. & $280^{\circ} \mathrm{C}$ \\
Ion source & $230^{\circ} \mathrm{C}$ \\
Scan range & $\mathrm{Mass}$ range $33-400$ \\
Ionisation energy & $70 \mathrm{eV}$ \\
GC transfer line & $280^{\circ} \mathrm{C}$ \\
\hline
\end{tabular}

Fig. 9 shows a schematic diagram of the micro-oven pyrolyzer Py-GC unit.

As done in Laboratory 1, the percentages of the identified compounds were determined on an area percent basis based on the total amount of peak area in the chromatogram. As such these numbers represent percentages of the amount of volatile product in the bio-oil and the specific numbers are also somewhat uncertain as the individual components are not individually calibrated for detector response. The reproducibility of the results of duplicate analyses was found to be excellent. Comparison of key pyrolytic decomposition markers for ETEK and ALM lignins is given in Fig. 10. In addition, the total percentages of identified compounds classed as benzenes, phenols, guaiacols, syringols, and carbohydrates are listed in Table 11 . These numbers compare favourably with those in Table 10 from Laboratory 1.

The significant amount of carbohydrate (cellulose and hemicellulose) degradation products (60.02\%), identified in the ETEK's chromatograms, support the assumption that the ETEK lignin is not

Table 11

Origin of the compounds identified by micro-oven pyrolyzer-GC/MS based on peak area

\begin{tabular}{lrr}
\hline & \multicolumn{1}{c}{ ALM } & \multicolumn{1}{c}{ ETEK } \\
\hline Carbohydrates & $5.22 \%$ & $60.02 \%$ \\
Guaiacols & $44.83 \%$ & $38.72 \%$ \\
Syringols & $33.69 \%$ & $0.00 \%$ \\
Phenols & $15.85 \%$ & $1.26 \%$ \\
HC & $0.40 \%$ & $0.00 \%$ \\
& $99.99 \%$ & $100.00 \%$ \\
\hline
\end{tabular}




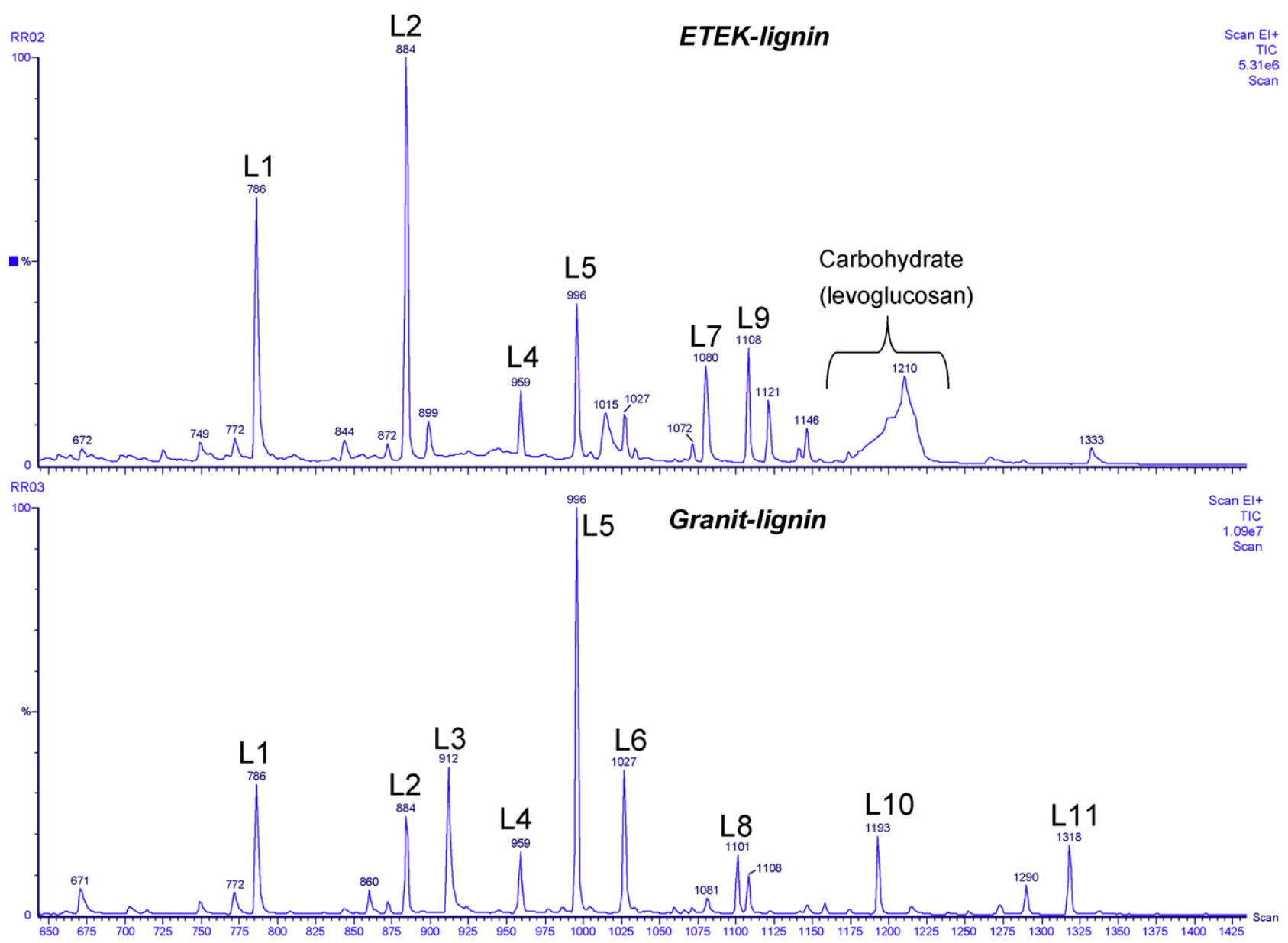

Fig. 12. Representative pyrograms of the lignin samples ETEK and ALM (Granit) performed without methylation.

a pure lignin, in contrast to the ALM lignin that contains very small amounts. The highest amount of guaiacols was identified in the ALM lignin's chromatogram along with a large fraction of syringols, suggesting herbaceous biomass source. The lack of syringols in the ETEK chromatograms suggests the softwood biomass source.

\subsection{Laboratory 14}

The analytical pyrolysis was performed using a filament pulse pyrolyzer (PYROLA 2000, Pyrol AB, Lund, Sweden). The pyrolysis chamber $\left(165^{\circ} \mathrm{C}\right)$ was purged with helium gas. The samples were pyrolyzed at around $630^{\circ} \mathrm{C}$. The GC/MS system consisted of a Hewlett Packard 5890 (GC) and a VG Trio-1 (MS) from Fisons Instruments. The capillary column used was a BPX5 low bleed/MS, $30 \mathrm{~m}$ by $0.25 \mathrm{~mm}$ i.d. (SGE). The temperature program was from $50{ }^{\circ} \mathrm{C}$ (hold for $2 \mathrm{~min}$ ), increasing at $24^{\circ} \mathrm{C} \mathrm{min}^{-1}$ to $320^{\circ} \mathrm{C}$ (hold for $12 \mathrm{~min})$. The mass spectrometer was operated in electron impact mode (+EI).

Many polar products, especially acids, are difficult to separate on the non-polar GC column. They are made less polar by methylation of the sample directly on the pyrolysis foil using tetramethylammonium hydroxide (TMAH).

The lignins were analysed both with and without methylation (TMAH). Representative pyrograms of each sample are shown in Figs. 11 and 12. The chemical structures of the main lignin-derived peaks are shown in Figs. 13 and 14. The relative amount of each compound identified is shown in Tables 12 and 13.
As can be seen from the results, there are substantial differences in the pyrolysis product composition between the two samples. The ETEK lignin produces products typical of a softwood lignin. The most significant difference between the samples is the presence of high amounts of carbohydrates in the ETEK lignin whereas the ALM lignin appears to be a more pure lignin sample. Some syringyl units from herbaceous lignin are also found in the ALM lignin products, but not in the ETEK lignin products.

Table 12

The relative amount of the identified pyrolysis products from analyses performed with methylation (TMAH) based on peak area.

\begin{tabular}{lrr}
\hline Lignin marker & ALM & ETEK \\
\hline 1 & 0 & 11 \\
2 & 4 & 0 \\
3 & 5 & 34 \\
4 & 2 & 0 \\
5 & 0 & 4 \\
6 & 6 & 8 \\
7 & 3 & 21 \\
8 & 0 & 2 \\
9 & 0 & 5 \\
10 & 1 & 0 \\
11 & 0 & 4 \\
12 & 2 & 8 \\
13 & 25 & 0 \\
14 & 2 & 0 \\
15 & 6 & 3 \\
16 & 44 & 0 \\
Total & 100 & 100 \\
\hline
\end{tabular}


<smiles>C=Cc1ccc(OC)cc1</smiles><smiles>C=Cc1ccc(OC)c(OC)c1</smiles><smiles>COc1ccc(C=CC(C)=O)cc1</smiles>

Fig. 13. Identified lignin-derived pyrolysis products from analyses performed with methylation (TMAH).

\subsection{Summary of analytical pyrolysis of lignin feedstocks}

The analytical pyrolysis results from these four laboratories consistently showed:

- ETEK lignin contained a substantial amount of non-lignin carbohydrate;

- ALM lignin was either herbaceous or hardwood-derived based on syringyl components;

- ETEK lignin lacked the syringols and therefore was softwood derived;
- Pyrolysis of lignins at $600^{\circ} \mathrm{C}$ or higher produced a much larger portion of volatile components in contrast to biomass pyrolysis which has been effectively analysed at $500^{\circ} \mathrm{C}$.

\section{Fast pyrolysis process tests with lignin feedstocks}

Seven laboratories carried out and reported fast pyrolysis experiments in bench-scale reactor systems. Feeding modifications were required in many cases. Two other laboratories were not able to effectively feed the ALM lignin into their reactors and did not try the ETEK lignin.<smiles>C=Cc1ccc(O)c(OC)c1</smiles><smiles>C=Cc1cc([14CH]=O)c(O)c(OC)c1</smiles>

Fig. 14. Identified lignin-derived pyrolysis products from analyses performed without methylation. 


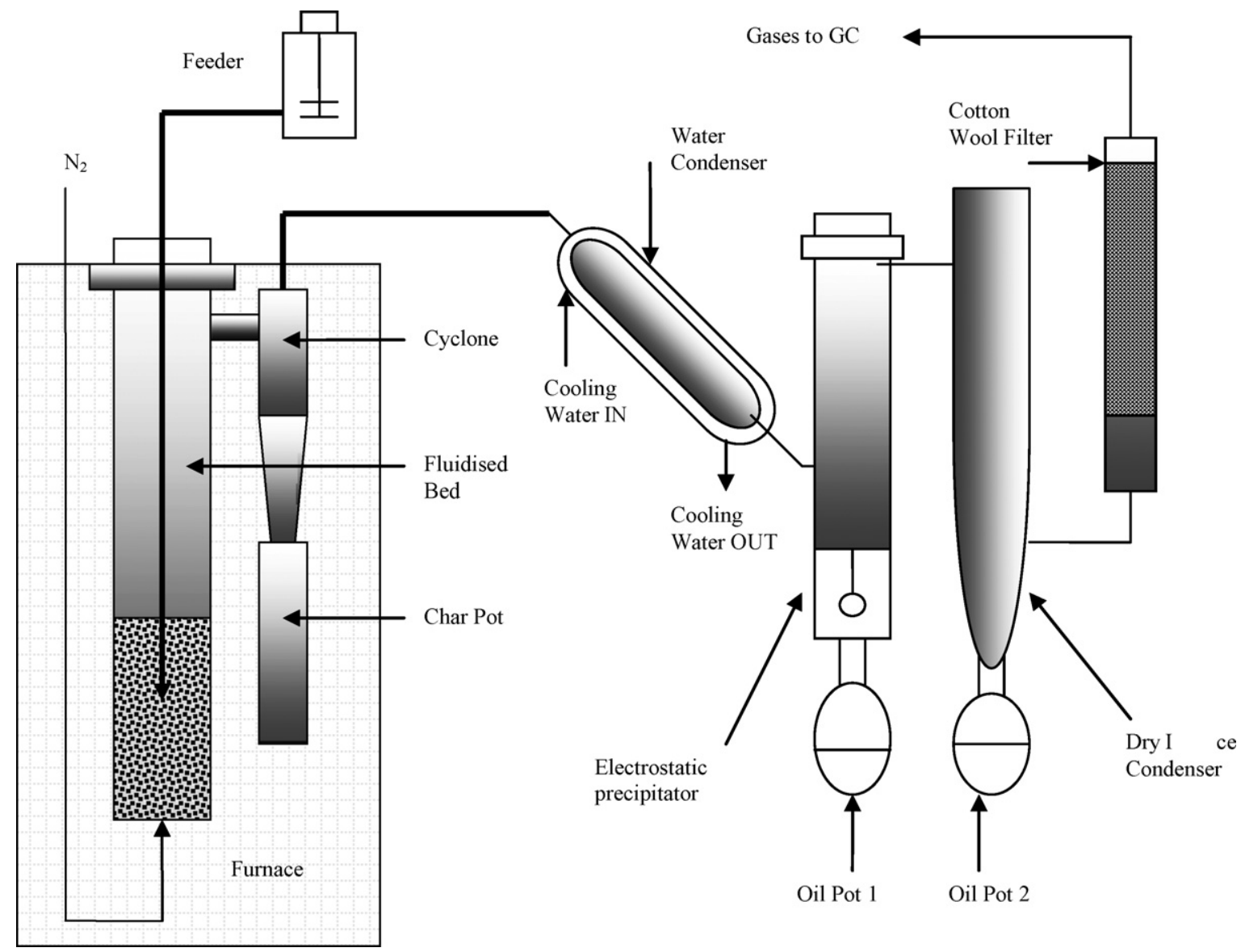

Fig. 15. $150 \mathrm{~g} / \mathrm{h}$ fluid bed test rig.

\subsection{Laboratory 1}

The $150 \mathrm{~g} / \mathrm{h}$ test rig, presented in Fig. 15, consisted mainly of a pneumatic feeder, a bubbling fluidized-bed reactor and a liquid product collection system. Nitrogen was used as the fluidized gas and sand $(150 \mathrm{~g})$ with particle size in the range of $355-500 \mu \mathrm{m}$ as the fluidizing and heat transfer medium. The reactor was placed in an electric muffle oven to provide the heat required for the process.

When the lignin was fed into the bed, heat was transferred from the sand to the biomass particles by conduction and convection and the biomass particles decomposed to vapours including aerosols, water and non-condensable gases and generated the residue solid char. The product mixture was carried out of the reactor through the cyclone where the solid was separated and collected in the

Table 13

The relative amount of the identified pyrolysis products from analyses performed without methylation based on peak area.

\begin{tabular}{lrr}
\hline Lignin marker & ALM & ETEK \\
\hline 1 & 12 & 27 \\
2 & 8 & 34 \\
3 & 16 & 0 \\
4 & 5 & 6 \\
5 & 32 & 14 \\
6 & 12 & 0 \\
7 & 0 & 10 \\
8 & 4 & 0 \\
9 & 0 & 9 \\
10 & 6 & 0 \\
11 & 5 & 0 \\
Total & 6 & 100 \\
\hline
\end{tabular}

char pot. The vapours together with some char fines that were not removed by the cyclone passed through a water-cooled condenser where they were partially condensed. The liquid together with the uncondensed vapours flowed into the electrostatic precipitator (ESP) where most of the uncondensed vapours together with aerosols and char fines were captured by the electrostatic charge supplied.

The liquid mixture was collected in a round bottom flask (oil pot 1) located under the ESP in full. The water and light volatile compounds such as formaldehyde, acetaldehyde and some ketones with low boiling points contained in the pyrolysis vapours were condensed by using a series of two dry ice/acetone condensers $\left(T=-30^{\circ} \mathrm{C}\right)$. Some light volatiles still escaped from the dry ice/acetone condensers due to their low partial pressure because of the dilution effect of the nitrogen carrier gas. These were captured in the cotton wool filter. After the cotton wool filter the nitrogen fluidizing gas together with the non-condensable pyrolysis gases passed through a gas meter where the volume of the exit gas was recorded. Then part of the mixture was pumped into an on-line chromatograph for gas composition analysis and the rest was vented.

In the case of lignin, pneumatic feeding in the fluidized-bed reactor proved impossible. As soon as the lignin reached the air-cooled feeding tube inside the fluidized-bed reactor, it melted and then partially decomposed to char resulting in a blockage. As a result, alternative batch feeding solutions were sought-after and tested, while the rest of the test rig remained unaltered. Firstly, a lock hopper configuration was tried consisting of two on/off ball valves and a nitrogen supply in between (see Fig. 16). The tube connected to the reactor had a water-cooled jacket to avoid any melting of the 


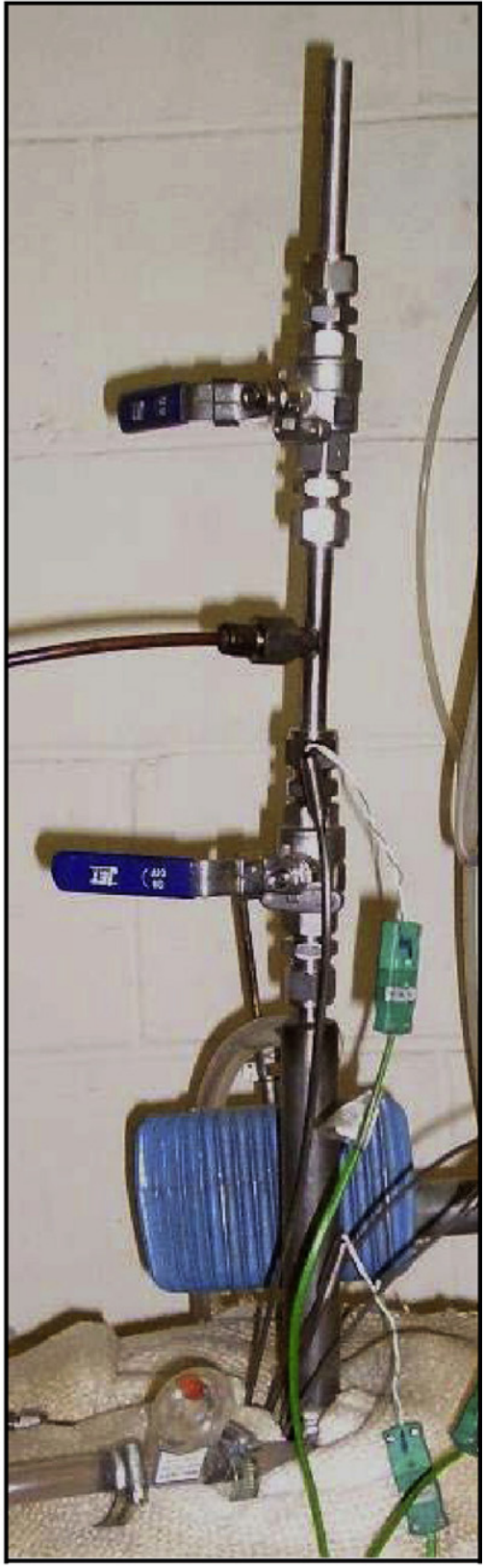

Fig. 16. Lock hopper.

lignin before entering the reactor. During a test run at $530^{\circ} \mathrm{C}, 25 \mathrm{~g}$ of Asian lignin were fed in batches of $2-3 \mathrm{~g}$. At the end of the run some heavy tar was collected in the condenser and some partially decomposed lignin in the ESP. No char had been collected by the cyclone and no bio-oil was collected in oil pot 1 . After dismantling the reactor it was observed that significant amounts of char were in the bed and they had caused bed agglomeration.

Since the first batch feeding configuration did not resolve all the problems, for example some partially decomposed lignin was found in the ESP, an alternative solution was tried. Due to the absence of any signs of melted lignin on the tube connected to the reactor, it was concluded that there was no need for a water jacket. Therefore, the configuration was simplified to one on/off ball valve and a push rod which was used to introduce the lignin inside the bed. The rod fitted exactly the diameter of the tube to avoid escape of gases and vapours (see Fig. 17). A test run was conducted with the simplified batch feeding system at $530^{\circ} \mathrm{C}$ with Asian lignin. Only about $9 \mathrm{~g}$ of
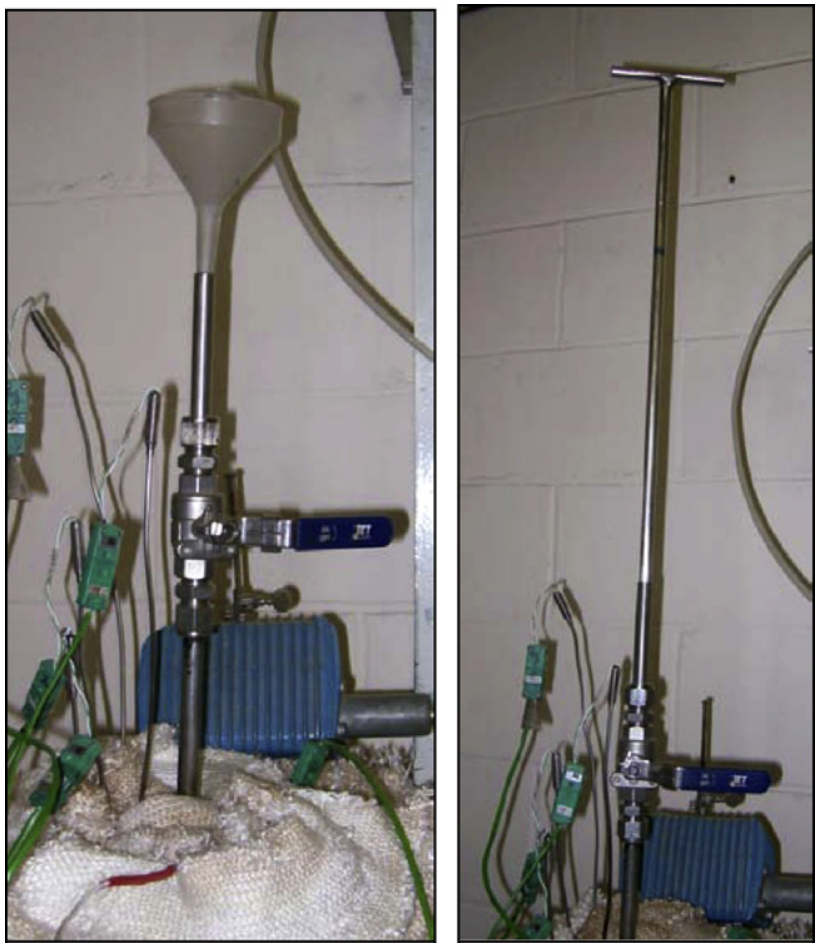

Fig. 17. Single valve with push rod.

lignin were fed due to the solidification of the fluidized bed from agglomeration of the sand and char.

The influence of the small particle size of lignin $(<100 \mu \mathrm{m})$ in the process was two-fold. Firstly, the dusty powder created a sticky layer inside the tube increasing the resistance of the push rod and hindering feeding. Secondly, the finer particles elutriated out of the reactor before decomposition, ending up in the ESP. In order to suppress these effects, a pretreatment process, adopted from the Laboratory 3 pretreatment procedure, yielding bigger particles was employed (see Fig. 18).

Another run was conducted at $530^{\circ} \mathrm{C}$ with the valve and push rod feeding system and the pretreated ALM lignin particles. About $100 \mathrm{~g}$ of lignin were fed in batches of $3 \mathrm{~g}$ every $2 \mathrm{~min}$. The run was stopped after $70 \mathrm{~min}$ due to the collapse of the fluidized bed caused by char and sand agglomeration. However, heavy tar was collected in the condenser and a mixture of bio-oil and partially decomposed lignin was collected in the ESP. It was noted that the lignin particles were easier to feed and the amount of partially decomposed lignin ending up in the ESP was reduced but not eliminated. Therefore the pretreatment had managed to resolve some of the problems caused by the small particle size. Still there was no char collected by the cyclone. The mass balance of this run is shown in Table 14.

ALM lignin char, tar deposits in condenser and deposits in ESP are presented in Figs. 19-21, respectively.

Table 14

Mass balance for pretreated ALM lignin.

\begin{tabular}{lrr}
\hline Mass balance (dry feed basis) & $\mathrm{g}$ & $\%$ \\
\hline Total feed less solid deposits (dry basis) & 83.78 & \\
Total pyrolysis liquids (estimated) & 26.18 & 31.2 \\
Organics (estimated) & 16.61 & 19.8 \\
Reaction water & 9.56 & 11.4 \\
Char & 40.88 & 48.8 \\
Gas & 4.74 & 5.7 \\
Closure & & 85.7 \\
\hline
\end{tabular}




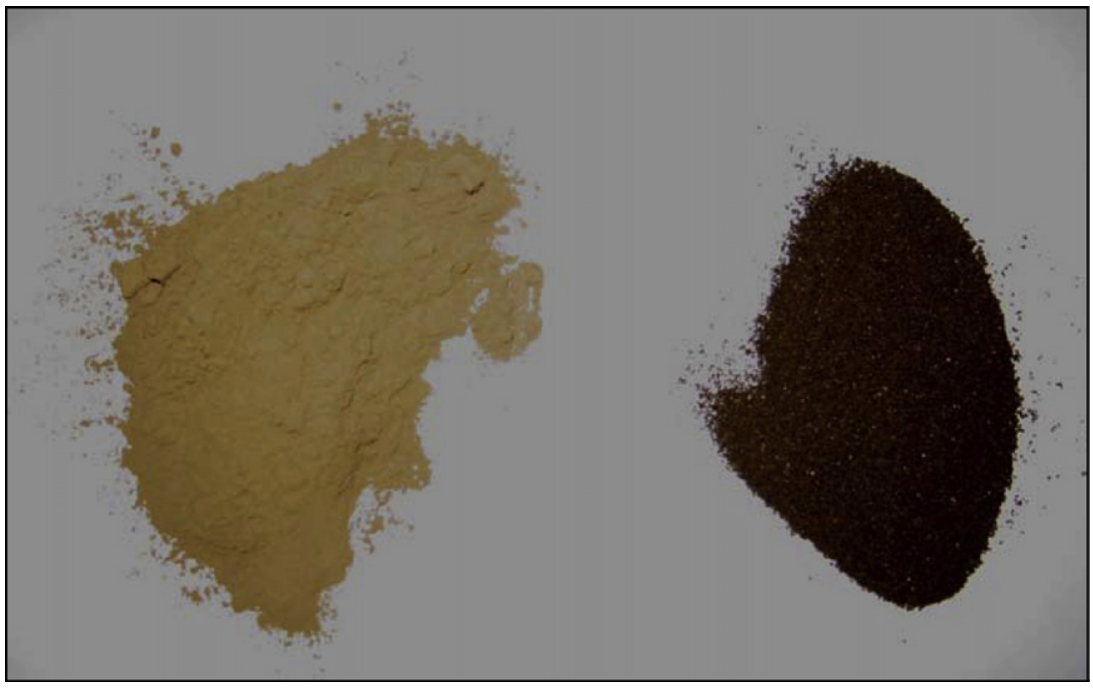

Fig. 18. ALM lignin before pretreatment $(<100 \mu \mathrm{m})$ (left) and after pretreatment $(355-1000 \mu \mathrm{m})$ (right).
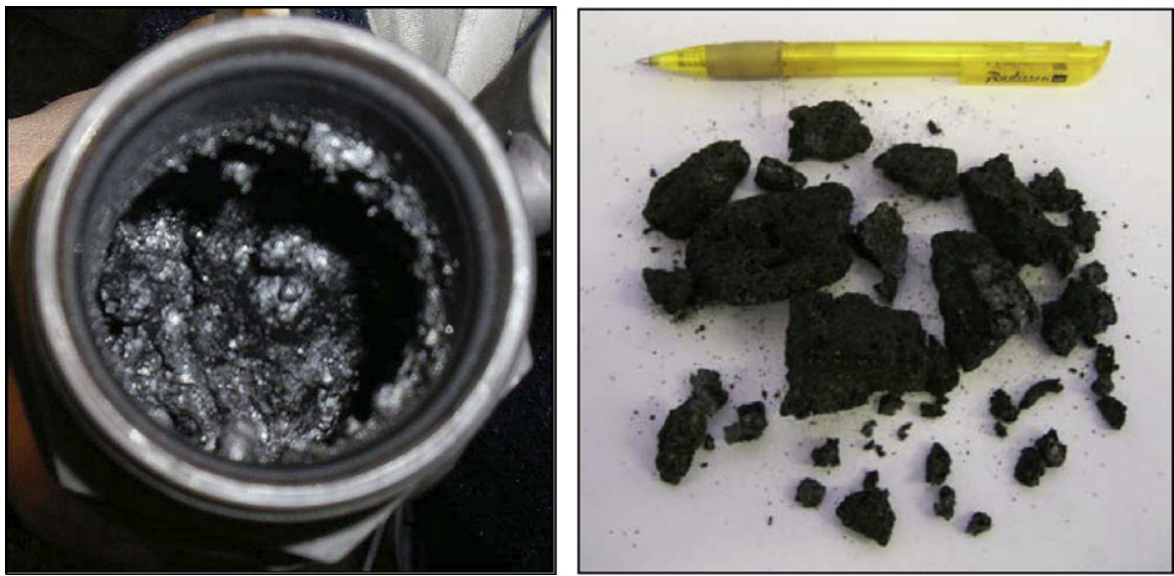

Fig. 19. Solid bed (left); Char removed from the bed after the run with pretreated ALM lignin (right).

The normalized product gas composition for the run conducted with the ALM lignin particles was $43 \%$ carbon dioxide, $32 \%$ methane and $18 \%$ carbon monoxide with no hydrogen and only traces of $\mathrm{C}_{2}$ and $C_{3}$ aliphatic and olefinic hydrocarbons.

Another run was conducted with the valve and push rod feeding system and the ETEK lignin at about $500^{\circ} \mathrm{C}$. About $44 \mathrm{~g}$ of lignin were fed. In contrast to the runs conducted with the ALM lignin, bio-oil was collected in oil pot 1 (see Fig. 22) and no partially decomposed lignin was found in the ESP. However, like the runs with the ALM lignin no char was collected by the cyclone and the bed experienced sand and char agglomeration (see Fig. 22), although not as

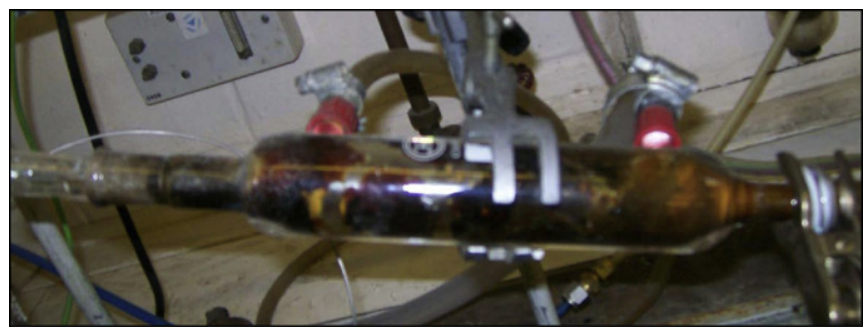

Fig. 20. Condenser with heavy tar deposits. extensive as that with the ALM lignin. The mass balance is shown in Table 15.

The normalized product gas composition from the run with ETEK lignin was 37\% carbon dioxide, 19\% methane and 39\% carbon monoxide with no hydrogen and only traces of $C_{2}$ and $C_{3}$ olefinic hydrocarbons.

With the valve and push rod feeding system the lignin was introduced in the freeboard of the reactor. Then the coarser fraction fell on the hot sand bed, bubbled and solidified causing bed agglomeration, while the finer fraction elutriated out of the reactor before decomposition and ended up in the ESP. Consequently, an appropriate feeding system needs to be developed to avoid the elutriation of

Table 15

Mass balance for ETEK lignin.

\begin{tabular}{lrc}
\hline Mass balance (dry feed basis) & $\mathrm{g}$ & $\%$ \\
\hline Total feed less solid deposits (dry basis) & 44.06 & \\
Total pyrolysis liquids & 25.42 & 57.7 \\
$\quad$ Organics & 19.96 & 45.3 \\
Reaction water & 5.46 & 12.4 \\
Char & 11.98 & 27.2 \\
Gas & 4.54 & 10.3 \\
Closure & & 95.2 \\
\hline
\end{tabular}



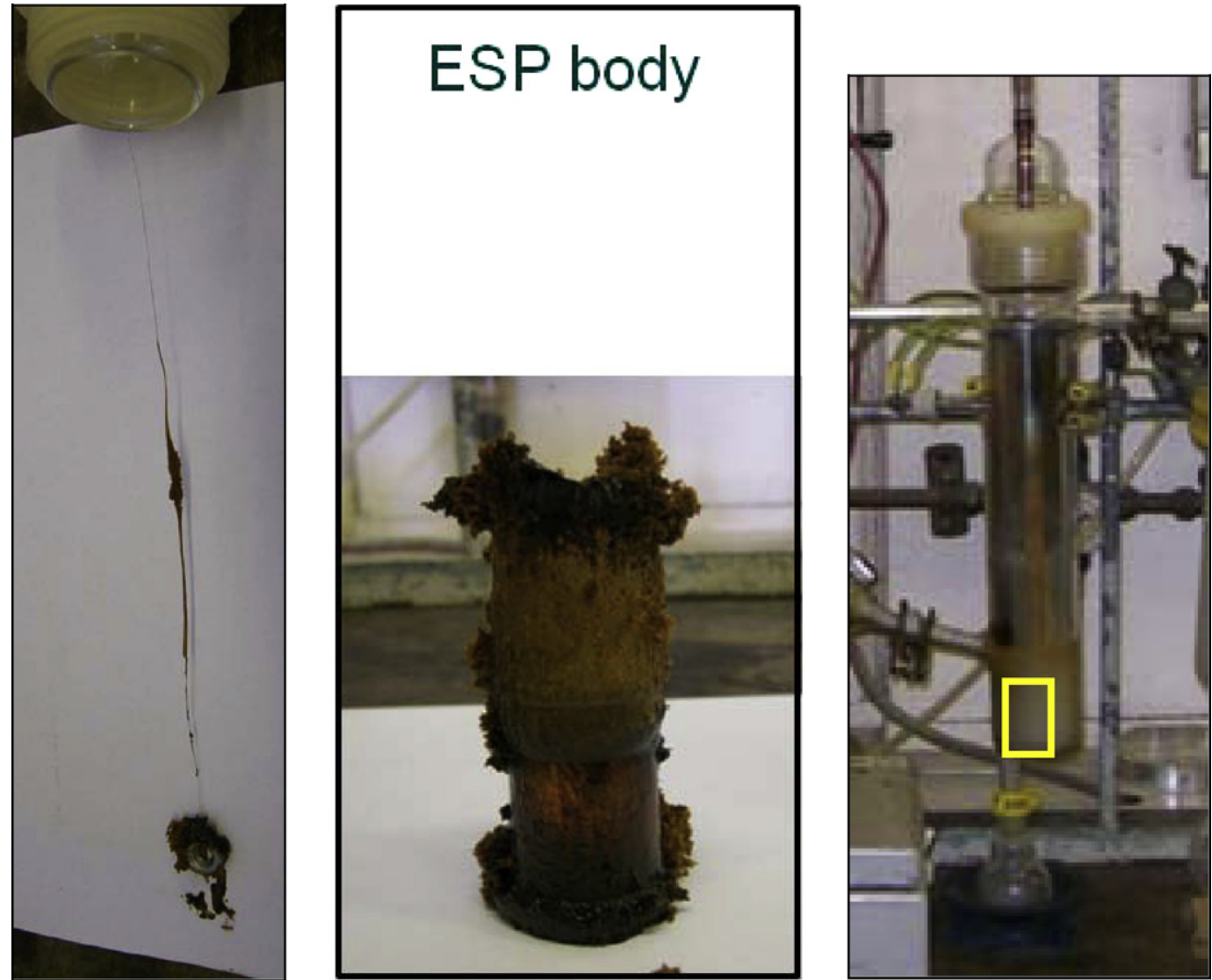

Fig. 21. ESP wire (left) ESP internal (middle) and assembly following test (right).

lignin out of the reactor before total decomposition. A screw feeder may resolve this problem. Moreover ways of controlling and minimizing bed agglomeration caused by the "bubbling" effect of lignin need to be investigated.

\subsection{Laboratory 3}

Both lignins were pyrolyzed in a bubbling fluidized-bed test facility (typical biomass feed rate $1 \mathrm{~kg} / \mathrm{h}$, see Fig. 23). This fluidizedbed test rig was not been specifically developed for fast pyrolysis. The sampling setup consisted of a high-temperature particle filter (soxhlet), Teflon adiabatic cooling tube, and a series of impinger bottles in which the pyrolysis gases and aerosols were effectively trapped in a solvent (iso-propanol) as described by tarweb [8]. In addition, a bio-oil collection pot was used consisting of an approximately $0.5 \mathrm{~L}$, water-cooled, double-walled steel vessel equipped with an internal particle/aerosol trap.

To allow use of the existing feed system, the ALM lignin had been brought in a feedable form by crushing and sieving an evaporated lignin/ethanol slurry as described in Fig. 24.

Dried lumps of the ETEK lignin were used as-received.

Using a standardised methodology for measuring biomass derived tars (European certified standard) the GC/FID-GC/MS characteristics of the lignin pyrolysis-oil were assessed. The distribution

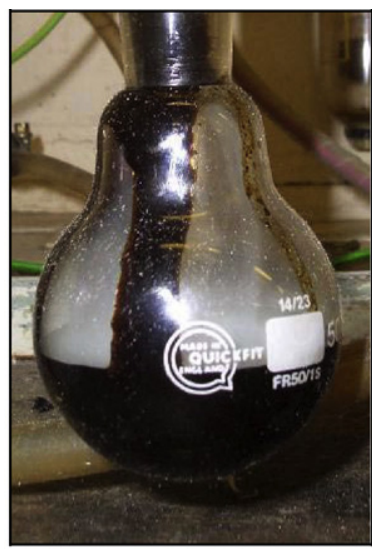

Bio-oil collected in oil pot 1 from the run with ETEK lignin

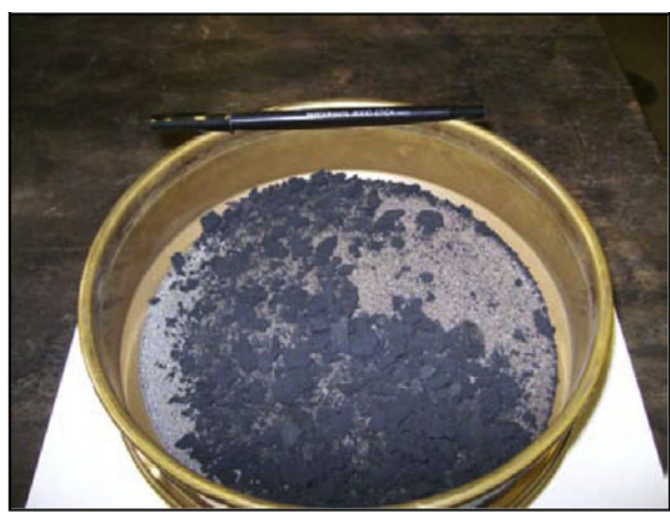

Char removed from the bed

Fig. 22. Products from ETEK lignin. 


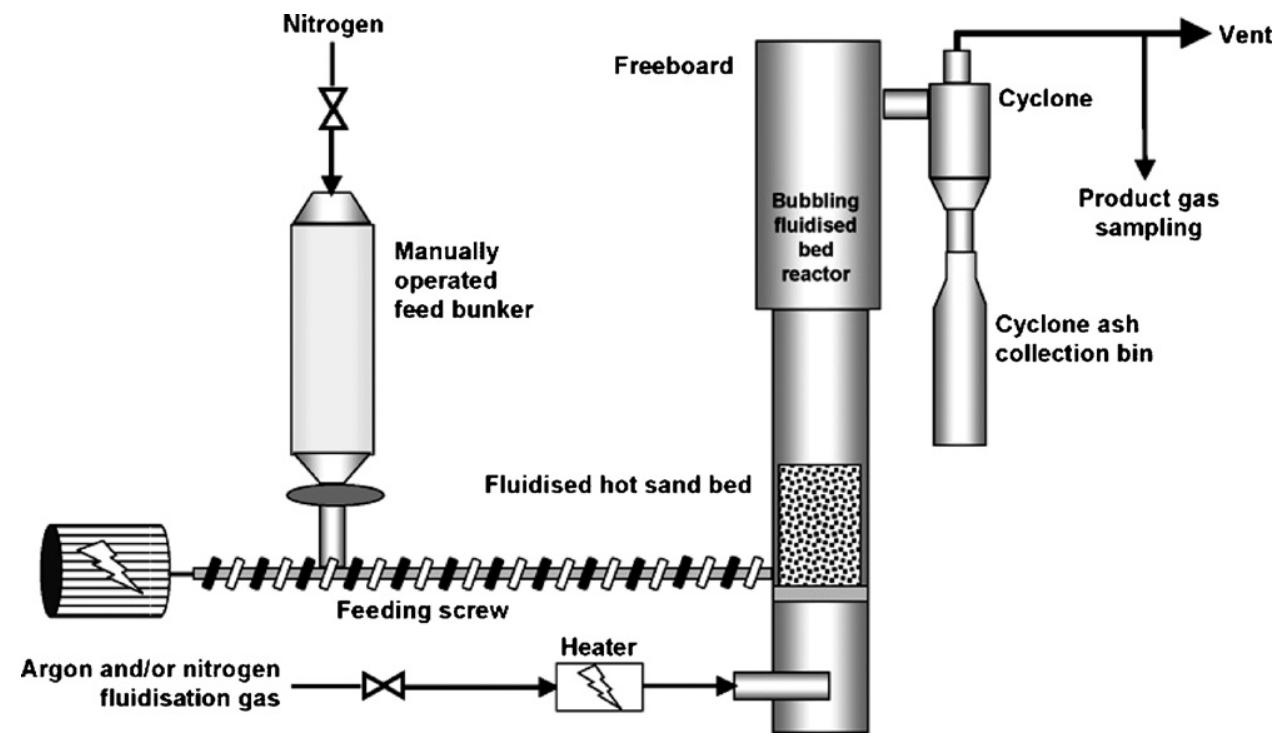

Fig. 23. Schematic of the bubbling fluidized-bed test facility.

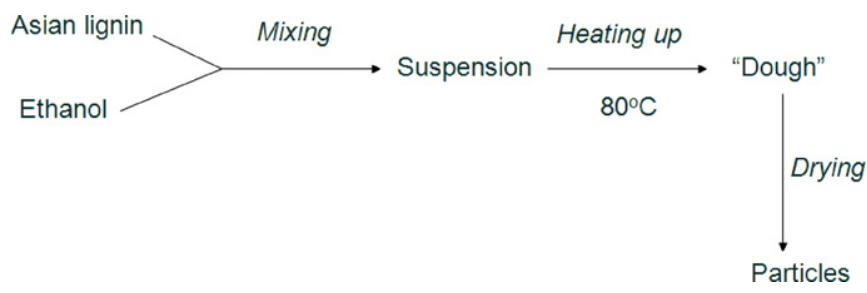

Fig. 24. Flow diagram of ALM lignin pretreatment.

of chemical products from fast pyrolysis experiments for ETEK and ALM lignin are compared in Fig. 25.

Pyrolysis of the ETEK lignin was successful, yielding approx. $38 \mathrm{wt}$.\% organic condensables of which only $1.4 \mathrm{wt} . \%$ were identified as monomeric phenols. The mass balance closure was estimated as 93\%. Pyrolysis of the ALM lignin was much more dif- ficult due to its melting behavior causing bed agglomeration and subsequent defluidization. In the second trial, a batch of $50 \mathrm{~g}$ ALM lignin was fed in a semi-continuous way with $10 \mathrm{~g}$ at a time. The time lapse in between two feedings was approximately 1-2 min. This feeding procedure appeared to be satisfactory, although some agglomeration could not be prevented, only slowed. The agglomerate grows until, inevitably, defluidization of the hot sand bed occurs. Large temperature gradients developed and the final situation was a poorly packed bed with a pumice-like black material sticking to the gas distribution plate and the reactor walls.

To investigate the effect of a lower reactor temperature the temperature of the sand bed was adjusted to $400^{\circ} \mathrm{C}$ instead of the prescribed $500^{\circ} \mathrm{C}$. Table 16 compares the yields of the GCdetectable species of the runs at 400 and $500^{\circ} \mathrm{C}$. Total organic yields are equal ( $11 \mathrm{wt} . \%$ based on the dry feedstock weight) with the experiment at $400^{\circ} \mathrm{C}$ with approximately 4 times more identified monomeric phenols than the experiment at $500^{\circ} \mathrm{C}$. This is partly

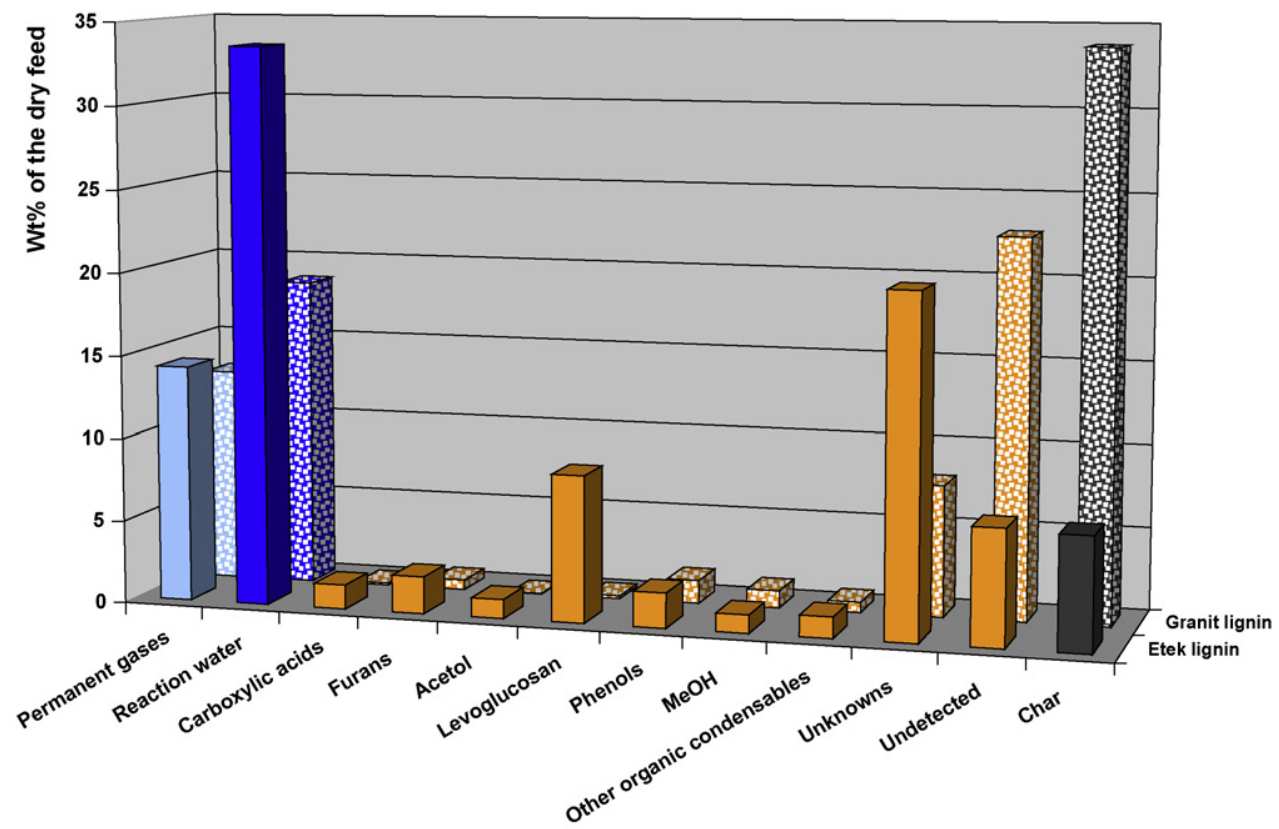

Fig. 25. Comparison of fast pyrolysis products for ETEK and ALM (Granit) lignins. 
Table 16

Yields of GC-detectable organics from the fast pyrolysis of ALM lignin at 400 and $500^{\circ} \mathrm{C}$.

\begin{tabular}{|c|c|c|}
\hline & $\begin{array}{l}500^{\circ} \mathrm{C} \\
\text { GC/FID } \\
\text { wt.\% dry basis }\end{array}$ & $\begin{array}{l}400^{\circ} \mathrm{C} \\
\text { GC/MS } \\
\text { wt. } \% \text { dry basis }\end{array}$ \\
\hline Methanol & 0.96 & 2.18 \\
\hline Acetaldehyde & 0.05 & \\
\hline Methylformate & 0.08 & \\
\hline Formic acid & 0.03 & 0.12 \\
\hline Acetic acid & 0.08 & \\
\hline Propanal + furan & 0.09 & \\
\hline Aceton + Isobutyraldehyde & 0.06 & 0.17 \\
\hline Me-acetate + Et-formate & 0.06 & \\
\hline 2-Butenal & 0.06 & \\
\hline Acetol & 0.03 & \\
\hline 1-Hydroxy-2-butanon & 0.02 & \\
\hline Angelicalactone & 0.03 & \\
\hline Furfural & 0.29 & 0.20 \\
\hline Methylfurfural & 0.03 & \\
\hline Furfurylalcohol & 0.02 & \\
\hline 2(5H)-Furanon & 0.02 & \\
\hline 5-Hydroxymethyl-2-furaldehyde & 0.06 & \\
\hline Levoglucosan & 0.16 & \\
\hline 3,4,5 Trimethoxytoluene & 0.03 & \\
\hline 1,2,4 Trimethoxybenzene & 0.15 & \\
\hline Guaiacol & 0.26 & 1.31 \\
\hline 4-Methyl-guaiacol & 0.20 & 0.69 \\
\hline 4-Ethylguaiacol & & 0.60 \\
\hline Eugenol & 0.02 & \\
\hline Isoeugenol & 0.17 & \\
\hline Syringol & 0.21 & 0.68 \\
\hline 4-Methylsyringol & & 0.33 \\
\hline Acetosyringone & & 0.29 \\
\hline Phenol & 0.40 & 0.41 \\
\hline 3-Ethyl phenol & 0.02 & \\
\hline 4-Ethyl phenol & & 0.30 \\
\hline Pyrocatechol & & 0.24 \\
\hline Hydroquinone & 0.03 & \\
\hline Unknowns & 7.4 & 3.4 \\
\hline Total yield monomeric phenols & 1.3 & 4.8 \\
\hline Total yield organic condensables & 11 & 11 \\
\hline
\end{tabular}

a Analysis method.

due to the "more sensitive" GC/MS analysis method. Consequently, the amount of unknowns is two times smaller when compared to the results obtained with the GC/FID analysis method. The quantitation is based on peak area and is not corrected for specific response; as such, it is only approximate. For both trials, mass balances could not be calculated for various reasons (like the formation of moltenlignin-sand clumps in the bed) but were estimated to be $70-80 \%$, at best. It was speculated that assuming that the amount of unknowns could be ascribed to (monomeric) phenolic substances, the overall amount of phenolic substances was roughly equal for both the pyrolysis experiments at $400^{\circ} \mathrm{C}$ and $500{ }^{\circ} \mathrm{C}$ (approx. $8 \mathrm{wt} . \%$ ).

\subsection{Laboratory 4}

Initial tests in Laboratory 4 were made with the ALM lignin. Fast pyrolysis experiments at about $500^{\circ} \mathrm{C}$ were performed in a fluidized-bed reactor with an auger screw feeder. Bio-oil was collected by a collection system of four condensers followed by an electrostatic precipitator (ESP). Feeding the powder feedstock was difficult due to melting of the lignin in the non-cooled auger feeder. Pelletizing the lignin provided little improvement as the pellets broke down to a similar powder in the feeder and melted in the auger, as shown in Fig. 26.

A very limited amount of bio-oil was collected in the ESP and the data is given in Table 17.

A more successful fast pyrolysis experiment of ETEK lignin was also reported. Prior to pyrolysis the lignin sample was dried at $60^{\circ} \mathrm{C}$

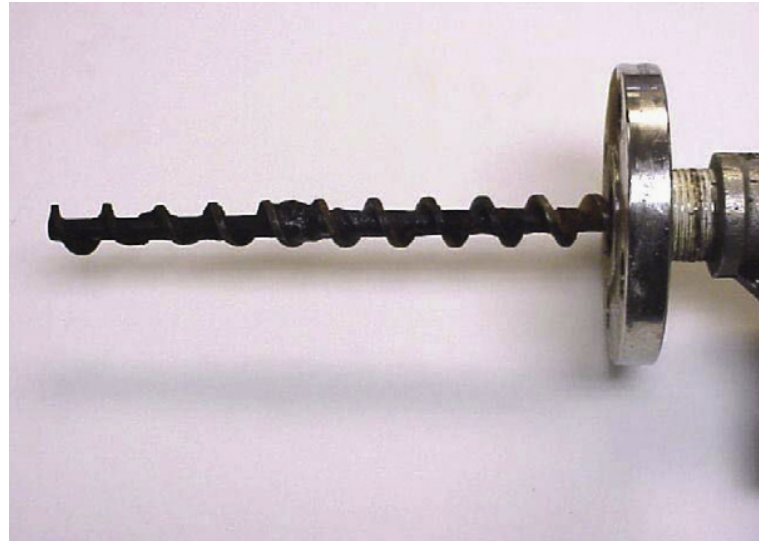

Fig. 26. Auger feeder with ALM lignin plug formed between flights.

in air flow for $24 \mathrm{~h}$ and then ground using a Wiley Mill with a $2 \mathrm{~mm}$ screen. Fast pyrolysis experiments at between 484 and $519^{\circ} \mathrm{C}$ were performed in the fluidized-bed reactor with the auger screw feeder cooled with dry ice. Bio-oil was collected by the same system of condensers followed by an ESP. The product gas composition (determined by Agilent Micro GC 3000, in line) was 66\% CO, 17\% $\mathrm{CH}_{4}, 12 \% \mathrm{H}_{2}, 5 \% \mathrm{CO}_{2}$ on a nitrogen-free basis.

Different fractions of bio-oil (collected in condensers 1-4 and ESP) were characterized using liquid GC and HPLC methods. An Agilent $6890 \mathrm{~N}$ GC with DB-1701 column ( $60 \mathrm{~m}$ by $0.25 \mathrm{~mm}$ with $0.25 \mu \mathrm{m}$ film thickness) with the injector heated to $250^{\circ} \mathrm{C}$ was used with a 1:30 split. Analysis was made using an Agilent 5973 MSD detector. The GC oven was set for $45^{\circ} \mathrm{C}$ for $40 \mathrm{~min}$ initially, then heated at $3^{\circ} \mathrm{C} / \mathrm{min}$ to $280^{\circ} \mathrm{C}$ and held for $20 \mathrm{~min}$. Samples were diluted in acetone. Fluoranthene was used as an internal standard. The quantitation is based on peak area and is not corrected for specific response; as such, it is only approximate. The HPLC was equipped with an Aminex HPX-87 column (300 mm $\times 7.8 \mathrm{~mm} @$ $30^{\circ} \mathrm{C}$ ) with a mobile phase of $0.007 \mathrm{~N} \mathrm{H}_{3} \mathrm{PO}_{4}$. 1-Propanol was used as an internal standard. The liquid components characterized by GC-MS and HPLC are given in Table 18.

\subsection{Laboratory 5}

The pyrolysis of the lignins in the normal fluidized-bed system failed in several attempts due to problems during feeding. Feeding time of only a few minutes led to either blockage of the screw feeder or loss of fluidization resulting from the formation of lignin-derived charred foam.

\section{Table 17}

Compounds identified in ALM lignin ESP bio-oil

\begin{tabular}{llll}
\hline RT & & Grouping & wt.\% \\
\hline N/A & Water (Karl Fischer) & & 2.52 \\
21.4 & 2-Methyl-2-cyclopenten-1-one & Ketone & 0.15 \\
26.5 & 3-Methyl-2-cyclopenten-1-one & Ketone & 0.32 \\
31.8 & Guaiacol & Phenol & 0.53 \\
36.6 & 2-Methoxy-4-methyl phenol & Phenol & 0.10 \\
48.4 & Isoeugenol & Phenol & 0.33 \\
45.2 & 2,6-Dimethoxy phenol & Phenol & 0.51 \\
31.0 & Phenol & Phenol & 4.77 \\
33.4 & o-Cresol & Phenol & 1.11 \\
34.0 & 2,5-Dimethyl phenol & Phenol & 0.10 \\
35.0 & p-Cresol & Phenol & 1.67 \\
35.1 & m-Cresol & Phenol & 0.99 \\
37.2 & 2,4-Dimethyl phenol & Phenol & 0.53 \\
38.9 & 3,5-Dimethyl phenol & Phenol & 0.21 \\
39.1 & 4-Ethyl phenol & Phenol & 1.28 \\
39.2 & 3-Ethyl phenol & Phenol & 0.20 \\
36.9 & 2-Ethyl phenol & Phenol & 0.16 \\
\hline
\end{tabular}



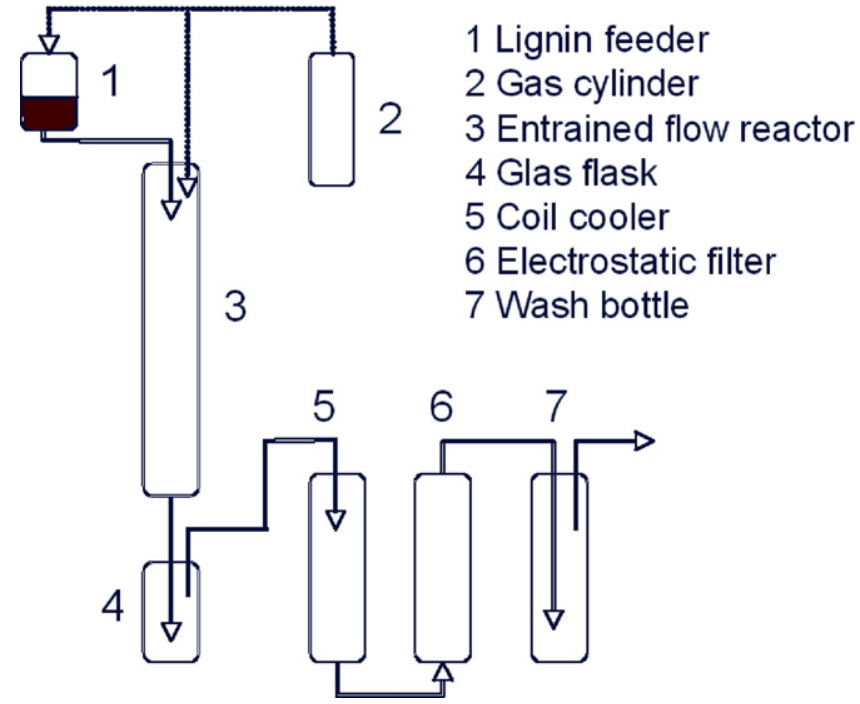

Fig. 27. Entrained-flow experimental setup.

An entrained-flow reactor system was devised which allowed fast pyrolysis results for both lignin feedstocks with operation at $700^{\circ} \mathrm{C}$ with a $1.5 \mathrm{~s}$ residence time. At these conditions the bio-oil yield was much lower than typical for fast pyrolysis of biomass, only $11.7 \%$ for ETEK lignin while the highest bio-oil yield, $36.6 \%$, was recovered for ALM lignin.

Feeding with the entrained-flow system (see Fig. 27) was accomplished with a double jacket lance cooled with running polyethyleneglycol at $-20^{\circ} \mathrm{C}$. Nitrogen was used as entraining gas. Feeding was much better than with the fluidized bed, but the feeding rate was rather slow $(40 \mathrm{~g} / \mathrm{h})$. The reactor was a quartz tube followed by a glass flask for char collection, a coil cooler and an electrostatic precipitator with subsequent wash bottle. Residence time was calculated as $0.7 \mathrm{~s}$. A qualitative comparison with the Py-GC/MS results revealed, that much more aromatic and phenolic structures were formed at the mitigation of typical lignin degradation products such as guaiacyl- and syringyl.

\subsection{Laboratory 6}

The ALM lignin was pyrolyzed in a fluidized-bed reactor system. The lignin was first pelletized and crushed to a particle size between 1 and $2 \mathrm{~mm}$. The fluidized quartz sand bed was fed $100 \mathrm{~g}$ lignin at a rate of $240 \mathrm{~g} / \mathrm{h}$ with a residence time in the bed of $1-2 \mathrm{~s}$. Condensate products were captured in two electrofilters operated at 8-10 and $4 \mathrm{kV}$. The condensate in the cooling traps was $93.1 \%$ water; there was a small amount of separate organic phase, $\sim 10 \%$, which was solid at room temperature.

\subsection{Laboratory 12}

A nominal $1 \mathrm{~kg} / \mathrm{h}$ fluidized-bed reactor was used to fast pyrolyze each of the lignin feedstocks. The bed was fluidized with nitrogen gas and operated in an overflow mode such that char and sand were continuously removed from the top of the bed and new sand was added with the lignin powder by a water-cooled screw [9]. The gas/vapour stream leaving the reactor contained sand fines and some char; a knock-out pot captured the sand and most of the char particles. Residual char in the vapour/gas stream was separated in cyclones and the bio-oil was collected by two condensing spray towers and a final condenser.

Operations with the ALM lignin were unsuccessful. Using a feed rate of only $500 \mathrm{~g} / \mathrm{h}$ the test extended for $2 \mathrm{~h}$. Early on there were problems with fluidization. Upon opening the reactor after the test the lignin and sand were found in large clumps (up to $5 \mathrm{~cm}$ in diameter) of very hard material. The feeding screw was also surrounded by solid lumps and at the feed entrance to the bed there was a $3 \mathrm{~cm}$ lump of lignin/sand on the screw.

Tests in a batch reactor were also attempted with the ALM lignin but did not produce enough bio-oil for analysis. Lumps of lignin were formed inside the reactor bed at an early stage of heating, as they were found after heating to $480^{\circ} \mathrm{C}$ and were not formed in cooldown. The pyrolysis of the small particles of lignin began very quickly (due to a short heat up time or by heating to less than the reactor temperature) yet continued reacting longer than a minute, which is longer than typical biomass.

There were no operational problems with the ETEK lignin; however, the lignin flow rate was reduced to only $100 \mathrm{~g} / \mathrm{h}$. The duration of the test was $3 \mathrm{~h}$ and the mass balance closure was 95\%. The normally used nitrogen overpressure on the feed screw was not used as the nitrogen blew the lignin dust through the screw and made feed control impossible. Also, a higher sand to feed ratio ( 8 versus 2 for typical biomass) was used. No lumps of lignin/sand were found in the reactor nor in the char collection components. The oil quality was poor, as it separated into two phases. There was a larger amount of gases and water produced than with typical biomass.

\subsection{Laboratory 13}

The Laboratory 13 fast pyrolysis rig (Fig. 28) includes a preheating chamber that heats the nitrogen before its entry in the reaction chamber and the main chamber where the biomass is pyrolyzed batch-wise in a fluidized bed of alumina. The lignin sample was pushed into the reactor using nitrogen. A tar trap was used to condense the condensable vapours into bio-oil and tar. The time for the thermo-chemical conversion was found to occur over 10 and $60 \mathrm{~s}$ although the residence time was estimated at $3-15 \mathrm{~s}$. As such, these are not actually fast pyrolysis results. The temperature considered during the experiment $\left(480^{\circ} \mathrm{C}\right)$ was measured by the thermocouple in connection with the alumina bed. The sample injection has been done four times for total $11.2 \mathrm{~g}$ of sample injected for each experiment. The experiments were repeated multiple times with each feedstock. In the case of the ALM lignin it was found that a portion of the feed melted in the injector and never

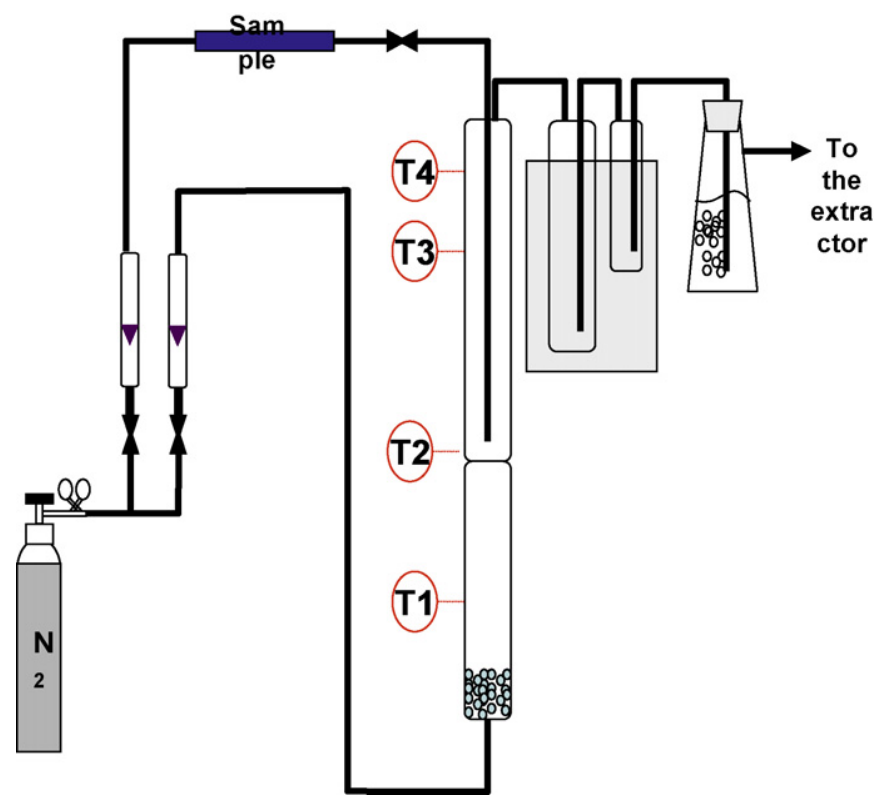

Fig. 28. Batch pyrolysis experimental setup. 
G Model

Table 18

Components of bio-oil obtained from ETEK lignin.

\begin{tabular}{|c|c|c|c|c|c|c|c|}
\hline Method & Compound & Grouping & Cond 1 & Cond 2 & Cond 3 and 4 & ESP & Total \\
\hline & $\%$ of Total Bio-oil & & 12.35 & 8.55 & 6.18 & 72.92 & 100.00 \\
\hline KF & Water & Water & 2.3 & 2.04 & 4.09 & 3.63 & 3.36 \\
\hline HPLC & Acetic acid & Acid & & 0.73 & 0.61 & 0.18 & 0.23 \\
\hline GC & Propionic acid & Acid & & $\mathrm{X}$ & $\mathrm{X}$ & & $\mathrm{X}$ \\
\hline GC & Hydroqunione & Alcohol & $\mathrm{X}$ & $\mathrm{X}$ & & $\mathrm{X}$ & $\mathrm{X}$ \\
\hline GC & Toluene & Aromatic & & & & $\mathrm{X}$ & $\mathrm{X}$ \\
\hline GC & Indene & Aromatic & & $\mathrm{X}$ & & $\mathrm{X}$ & $\mathrm{X}$ \\
\hline GC & Naphthalene & Aromatic & $\mathrm{X}$ & $\mathrm{X}$ & $\mathrm{X}$ & $\mathrm{X}$ & $\mathrm{X}$ \\
\hline GC & Methyl napthalene & Aromatic & $\mathrm{X}$ & $\mathrm{X}$ & $\mathrm{X}$ & $\mathrm{X}$ & $\mathrm{X}$ \\
\hline GC & 1-Ethyl-4-methoxybenzene & Ether & $\mathrm{X}$ & $\mathrm{X}$ & $\mathrm{X}$ & $\mathrm{X}$ & $\mathrm{X}$ \\
\hline GC & Butyrolactone & THFuran & $\mathrm{X}$ & $\mathrm{X}$ & $\mathrm{X}$ & $\mathrm{X}$ & $\mathrm{X}$ \\
\hline GC & Furfural & Furan & 0.17 & 0.2 & 0.26 & 0.31 & 0.28 \\
\hline GC & Furfuryl alcohol & Furan & & 0.1 & 0.18 & 0.02 & 0.03 \\
\hline GC & 1-(2-Furanyl)-ethanone & Furan & $\mathrm{X}$ & $\mathrm{X}$ & $\mathrm{X}$ & $\mathrm{X}$ & $\mathrm{X}$ \\
\hline GC & 4-Methyl-5H-furan-2-one & Furan & $\mathrm{X}$ & $\mathrm{X}$ & $\mathrm{X}$ & $\mathrm{X}$ & $\mathrm{X}$ \\
\hline GC & 2-Methyl-2-cyclopenten-1-one & Ketone & & 0.11 & & 0.02 & 0.02 \\
\hline GC & 3-Methyl-2-cyclopenten-1-one & Ketone & & 0.12 & & 0.04 & 0.04 \\
\hline GC & Corylone & Ketone & $\mathrm{X}$ & $\mathrm{X}$ & $\mathrm{X}$ & $\mathrm{X}$ & $\mathrm{X}$ \\
\hline GC & 3-Ethyl-2-cyclopenten-1-one & Ketone & & $\mathrm{X}$ & $\mathrm{X}$ & $\mathrm{X}$ & $\mathrm{X}$ \\
\hline GC & 2,3-Dihydroxy-1H-inden-1-one & Ketone & $\mathrm{X}$ & $\mathrm{X}$ & & $\mathrm{X}$ & $\mathrm{X}$ \\
\hline GC & Hydroxyacetaldehyde & Oxygenates & $\mathrm{X}$ & $\mathrm{X}$ & $\mathrm{X}$ & $\mathrm{X}$ & $\mathrm{X}$ \\
\hline HPLC & Acetol & Oxygenates & 0.58 & 2.29 & 4.79 & 2.74 & 2.56 \\
\hline GC & 4-Hydroxy-4-methyl-2-pentanone & Oxygenates & 0.09 & 0.1 & & 0.08 & 0.08 \\
\hline GC & Guaiacol & Phenol & 0.36 & 0.43 & 0.36 & 0.38 & 0.38 \\
\hline GC & 2-Methoxy-4-methyl phenol & Phenol & 0.32 & 0.37 & 0.25 & 0.31 & 0.31 \\
\hline GC & Eugenol & Phenol & $\mathrm{X}$ & $\mathrm{X}$ & $\mathrm{X}$ & $\mathrm{X}$ & $\mathrm{X}$ \\
\hline GC & Isoeugenol & Phenol & 0.24 & 0.27 & $\mathrm{X}$ & $\mathrm{X}$ & $\mathrm{X}$ \\
\hline GC & 2,6-Dimethoxy phenol & Phenol & $\mathrm{X}$ & $\mathrm{X}$ & $\mathrm{X}$ & & $\mathrm{X}$ \\
\hline GC & Phenol & Phenol & 0.68 & 0.86 & 0.9 & 0.62 & 0.67 \\
\hline GC & o-Cresol & Phenol & 0.30 & 0.36 & 0.33 & 0.28 & 0.29 \\
\hline GC & 2-Hydroxy-5-methyl benzaldehyde & Phenol & $\mathrm{X}$ & $\mathrm{X}$ & $\mathrm{x}$ & $\mathrm{X}$ & $\mathrm{X}$ \\
\hline GC & p-Cresol & Phenol & 0.33 & 0.42 & 0.31 & 0.27 & 0.29 \\
\hline GC & m-Cresol & Phenol & 0.30 & 0.37 & 0.28 & 0.27 & 0.28 \\
\hline GC & 2,4-Dimethyl phenol & Phenol & 0.27 & 0.28 & 0.21 & 0.25 & 0.25 \\
\hline GC & 2,4,6-Trimethyl phenol & Phenol & $\mathrm{X}$ & $\mathrm{X}$ & $\mathrm{X}$ & $\mathrm{X}$ & $\mathrm{X}$ \\
\hline GC & 3,5-Dimethyl phenol & Phenol & 0.13 & 0.05 & 0.02 & 0.09 & 0.09 \\
\hline GC & 4-Ethyl phenol & Phenol & 0.12 & 0.16 & 0.09 & 0.12 & 0.12 \\
\hline GC & 3-Ethyl phenol & Phenol & 0.06 & 0.07 & 0.04 & 0.05 & 0.05 \\
\hline GC & 2-Ethyl phenol & Phenol & 0.05 & 0.06 & 0.04 & 0.04 & 0.04 \\
\hline GC & 4-Ethyl-3-methyl phenol & Phenol & $\mathrm{x}$ & $\mathrm{X}$ & $\mathrm{X}$ & $\mathrm{x}$ & $\mathrm{x}$ \\
\hline GC & Vanillin & Phenol & $\mathrm{X}$ & $\mathrm{X}$ & $\mathrm{X}$ & $\mathrm{X}$ & $\mathrm{X}$ \\
\hline GC & 2,3-Anhydro-D-mannosan & Sugar & & & & $\mathrm{X}$ & $\mathrm{X}$ \\
\hline GC & 1,4:3,6-Dianhydro- $\alpha$-D-glucopyranose & Sugar & & $\mathrm{X}$ & $\mathrm{X}$ & $\mathrm{X}$ & $\mathrm{X}$ \\
\hline HPLC & Levoglucosan & Sugar & 2.05 & 12.87 & 3.62 & 11.64 & 10.07 \\
\hline
\end{tabular}

$\mathrm{X}=$ detected but not quantified.

Table 19

Comparative data from different pyrolysis tests.

\begin{tabular}{|c|c|c|c|c|c|c|c|}
\hline & Lab 1 & Lab 3 & Lab 4 & Lab 6 & Lab 12 & Lab 5 & Lab 13 \\
\hline \multicolumn{8}{|l|}{ ETEK } \\
\hline Feeder & Valve and push rod & N2 cooled screw & Dry ice-cooled screw & No result & Water-cooled screw & Entrained in nitrogen & $\begin{array}{l}\text { Entrained in } \\
\text { nitrogen }\end{array}$ \\
\hline Reactor & Fluidized bed & Fluidized bed & Fluidized bed & No result & Fluidized bed & Entrained flow & Batch \\
\hline Temperature & 500 & $450-510$ & 484-519 & No result & 500 & 700 & 480 \\
\hline Time & & $0.3-0.5$ & 0.1 & No result & 1.7 & 1.5 & $3-15$ \\
\hline Bio-oil yield & 57.7 & 72 & $40.1(79.6)^{\mathrm{a}}$ & No result & $47^{b}$ & 11.7 & 40 \\
\hline Char yield & 27.2 & 7 & 13.9 & No result & 25 & 48.8 & 30 \\
\hline Gas yield & 10.3 & 14 & 6.5 & No result & 23 & $39.5^{\mathrm{a}}$ & $30^{\mathrm{a}}$ \\
\hline \multicolumn{8}{|l|}{ ALM } \\
\hline Feeder type & Valve and push rod & N2 cooled screw & No result & & No result & Entrained in nitrogen & $\begin{array}{l}\text { Entrained in } \\
\text { nitrogen }\end{array}$ \\
\hline Reactor type & Fluidized bed & Fluidized bed & No result & Fluidized bed & No result & Entrained flow & Batch \\
\hline Temperature $\left({ }^{\circ} \mathrm{C}\right)$ & 530 & $410-560$ & No result & $475-525$ & No result & 700 & 480 \\
\hline Time $(s)$ & & $0.3-0.5$ & No result & $1-2$ & No result & 1.5 & $3-15$ \\
\hline Bio-oil yield (\%) & 31.3 & 31 & No result & $49.7^{b}$ & No result & 36.6 & 22 \\
\hline Char yield (\%) & 48.8 & 34 & No result & 42.3 & No result & 35.5 & 48.3 \\
\hline Gas yield (\%) & 5.7 & 12 & No result & 8.0 & No result & $27.9^{\mathrm{a}}$ & $29.7^{\mathrm{a}}$ \\
\hline
\end{tabular}

a By difference.

b Two phase condensate product. 
Table 20

Comparative data of different pyrolysis product bio-oils.

\begin{tabular}{|c|c|c|c|c|c|}
\hline & Lab 3 & Lab 4 & Lab 6 & Lab 12 & Lab 13 \\
\hline \multicolumn{6}{|l|}{ ETEK } \\
\hline Water content & 34 & 3.4 & No result & 48 & $<11$ \\
\hline Viscosity & ND & ND & No result & $21 \mathrm{cps}$ & ND \\
\hline $\mathrm{pH}$ & ND & ND & No result & 3.51 & ND \\
\hline Filterable solids & ND & 1.0 & No result & 1.4 & 13.6 \\
\hline Carbon & 47 & ND & No result & 28 & 53.7 \\
\hline Hydrogen & 6.8 & ND & No result & 9 & 6.8 \\
\hline Nitrogen & 0.8 & ND & No result & ND & ND \\
\hline Pyrolytic lignin & ND & 22.5 & No result & $18.37^{a}$ & ND \\
\hline \multicolumn{6}{|l|}{ ALM } \\
\hline Water content & 19 & No result & ND & No result & $<15$ \\
\hline Viscosity & ND & No result & ND & No result & ND \\
\hline $\mathrm{pH}$ & ND & No result & $\sim 4.5$ & No result & ND \\
\hline Filterable solids & ND & No result & ND & No result & 15 \\
\hline Carbon & 54 & No result & ND & No result & 60.8 \\
\hline Hydrogen & 6 & No result & ND & No result & 7.4 \\
\hline Nitrogen & 0.6 & No result & ND & No result & ND \\
\hline Pyrolytic lignin & ND & No result & ND & No result & ND \\
\hline
\end{tabular}

a Water insoluble "pyrolytic lignin" may contain extractives.

made it into the reactor. The products after the experiments were bio-oil, char and gas.

The weight difference of the collection bottles was measured to determine the bio-oil yield; the weigh difference between the alumina + char minus the initial alumina weigh determined the char yield (including the ash content). The gas yield was not measured. The bio-oils were collected in a container using 50/50 solution of dichloromethane and methanol.

\subsection{Summary comparison of fast pyrolysis tests}

The results of the various bench-scale pyrolysis tests are compared in Table 19. The yield of bio-oil is much lower for both lignin and remarkedly lower for the more pure ALM lignin. Processing in conventional fluidized-bed fast pyrolysis systems is difficult with either lignin but nearly impossible with the ALM lignin. "Melting" of the lignin. Probably resulting from lower temperature decomposition caused the feeding systems to plug. Further decomposition and polymerization led to formation of adhered clumps of bed material and lignin coke in the fluidized beds and eventually led to loss of fluidization. Pyrolysis at higher temperature in entrained-flow systems seems to provide an operating option.

The bio-oil products from these tests were analysed by some of the participants. The results are provided in Table 20. Note that Laboratories 1 and 5 did not undertake any of these product analyses. The product was highly variable probably reflecting that some of the laboratories actually produced product oils with more than one phase. The high solids contents in the products from Laboratory 13 reflect the batch reactor mode without a cyclone cleanup step. The bio-oil from the ALM lignin appears to have a higher carbon content.

\section{Conclusions}

The work leads to the following conclusions:

\subsection{Thermogravimetric analysis}

- Decomposition of the ALM lignin starts at $120^{\circ} \mathrm{C}$ and extends over a wider temperature range than the decomposition of the ETEK lignin.

- The ETEK lignin appears to behave more like whole biomass than lignin.

\subsection{Analytical pyrolysis}

- ETEK lignin is not a pure lignin as indicated from the high amount of identified carbohydrate derivatives (39.46\%) in contrast to the ALM lignin.

- The ETEK lignin products suggest a softwood source while the ALM lignin appears to have either a hardwood or herbaceous source.

\subsection{Laboratory scale reactor systems}

- Both lignins were prone to plugging in pneumatic or screw feeders which were not cooled due to their low melting point.

- ALM lignin bubbled as soon as it was fed in the reactor and formed highly porous char that eventually caused bed agglomeration.

- With ETEK lignin, bed agglomeration also occurred, but was less severe compared to that with ALM lignin.

- Because of the very small particle size $(<100 \mu \mathrm{m})$ part of the lignin fed seemed to escape from the reactor without decomposition, carry through the cyclones, and end up in the product oil collectors.

- ALM lignin produced a heavy tarry bio-oil in a lower quantity than a whole biomass; conversely the char yields were higher.

- The bio-oil from the lignins was similar to typical bio-oil confirming the source of bio-oil components often speculated in the literature, i.e., the ETEK lignin produced a collection of oxygenates along with phenolics while the ALM lignin produced primarily phenolic components.

- ETEK lignin contained a large portion of cellulose and behaved more like high-lignin wood.

- A modified processing system will be required for fast pyrolysis of actual lignin.

\section{Recommendations}

Lignin cannot be effectively fast pyrolyzed in reactor systems designed for whole biomass materials. However, less purified lignin products, as derived in some hydrolysis-based systems, may be suitable feedstock in conventional fast pyrolysis with minor adjustments for temperature control in feeding and product collection methods. For effective liquefaction of high-purity lignin by pyrolysis, new reactor designs, such as entrained-flow, operated at different conditions, such as higher temperature and longer residence time, will be required. Lignin-derived bio-oil is produced in 
lower yield and the char byproduct is a larger fraction; however, the bio-oil appears to contain less oxygen and as a result is expected to have a higher energy density.

\section{References}

[1] D.W. Goheen, in: I.S. Goldstein (Ed.), Organic Chemicals from Biomass, CRC Press, Inc., Boca Raton, FL, USA, 1981, p. 143.

[2] G.G. Allan, T. Mattila, in: K.V. Sarkanen, C.H. Ludwig (Eds.), Lignins-Occurrence, Formation Structure and Reactions, Wiley Interscience, New York, London, Sydney, 1971, p. 575.
[3] C. Amen-Chen, H. Pakdel, C. Roy, Bioresour. Technol. 79 (2001) 277.

[4] P.F. Britt, A.C. Buchanan, M.K. Kidder, Preprints of Symposia, 288-289, American Chemical Society, 2008.

[5] A.V. Bridgwater, D. Meier, D. Radlein, Org. Geochem. 30 (1999) 1479

[6] http://www.asianlignin.com/pages/products1.html.

[7] F. Shafizadeh, in: R.P. Overend, T.A. Milne, L.K. Mudge (Eds.), Fundamentals of Thermochemical Biomass Conversion, Elsevier Applied Science Publishers, London, 1985, p. 183, Chapter 11.

[8] http://www.tarweb.net/.

[9] R.J.M. Westerhof, N.J.M. Kuipers, S.R.A. Kersten, W.P.M. van Swaaij, Ind. Eng. Chem. Res. 46 (2007) 9238. 